\title{
Identifying Sciaenid Critical Spawning Habitats by the Use of Passive Acoustics
}

\author{
JosePH J. LuCZKOVICH* \\ Department of Biology and Institute for Coastal and Marine Resources, \\ East Carolina University, Greenville, North Carolina 27858, USA \\ R. Christopher Pullinger \\ North Carolina Division of Water Quality, \\ 943 Washington Square Mall, Washington, North Carolina 27889, USA \\ STEPHEN E. JoHNSON \\ Department of Biology, East Carolina University, Greenville, North Carolina 27858, USA \\ Mark W. Sprague \\ Department of Physics, East Carolina University, Greenville, North Carolina 27858, USA

\begin{abstract}
Sounds produced by spawning fishes in Pamlico Sound, North Carolina, have been recorded both under captive conditions and in hydrophone and sonobuoy field surveys. These sounds, produced by males, are species specific, are associated with spawning, and are most likely used for advertisement to attract females. Sounds can be discriminated by use of spectral analysis (oscillograms and spectrograms) of recordings, and the peak frequencies produced by each species can be correlated with species and fish size. Sonobuoys were used for passive acoustic surveys, which were "sound truthed" from recordings of captive fishes to determine the timing and location of spawning sites for four species in the family Sciaenidae: red drum Sciaenops ocellatus, spotted seatrout Cynoscion nebulosus, weakfish C. regalis, and silver perch Bairdiella chrysoura. During May-September 1998, sounds were first detected in the early evening, increased in loudness after sunset, and ended by sunrise. Weakfish and silver perch were heard predominantly at inlet locations in May and June, whereas spotted seatrout (peak drumming in July) and red drum (peak drumming in September) were heard predominantly at lower-salinity river mouth locations in western Pamlico Sound. Passive acoustic surveys can be used to determine critical spawning habitats of sciaenid fishes; such surveys have revealed interesting insights into fish behavior and should be integrated into ocean observing systems.
\end{abstract}

Knowledge of spawning habitats and estimating spawning stock biomass is essential for the conservation of exploited fish stocks. For example, in the USA, one requirement of the Sustainable Fisheries Act is the assessment of essential fish habitat (EFH) for all fishery management plans. Identification and mapping of EFH constitute an area of active research by fishery biologists (Benaka 1999). In addition, marine reserves and closure of fishing areas have been proposed for conservation of exploited fish stocks (Clark 1996; Ogden 1997; Roberts 1997; Allison et al. 1998; Guenette et al. 1998; Lauck et al. 1998). The establishment of EFH and marine reserves and the accurate estimation of spawning stock biomass require knowledge of the location of spawning and nursery areas for fishes. A direct measurement of both the

\footnotetext{
* Corresponding author: luczkovichj@ecu.edu
}

Received November 18, 2005; accepted June 19, 2006 Published online April 3, 2008 spawning areas and the spawning stock present in those areas is desirable.

Hydroacoustics, which can provide information about spawning habitats used by fishes, is broadly divided into two areas: active acoustics and passive acoustics. Active acoustics is well established in fishery biology as a method using high-frequency echosounders $(>10 \mathrm{kHz})$ to estimate abundance of the fishes and their habitat (MacLennan and Simmons 1992). One area that is still problematic for active acoustic approaches is remote species identification (Horne 2000); a solution is passive acoustic approaches, which can be used to identify species (Sprague et al. 2000). Passive acoustics also has a long history in fish biology (Tower 1908; Burkenroad 1931; Fish and Mowbray 1970; Mok and Gilmore 1983; Luczkovich et al. 1999, 2000) but is not widely used by fishery biologists. In passive acoustics, low-frequency sounds $(<10 \mathrm{kHz})$ produced by certain species of soundproducing (soniferous) fishes are used to determine species identity and use of particular habitats (Luczko- 
vich et al. 1999). Passive acoustics requires the use of specialized methods, equipment, and computer algorithms to record and process the low-frequency sounds, and these may be unfamiliar to fishery biologists. In this paper, we will concentrate on the use of passive acoustics to identify spawning habitats of sciaenid fishes in North Carolina.

Location of spawning areas is a difficult task using traditional fishery sampling. One approach involves mapping the distribution of eggs, larvae, or pelagic juvenile fishes. The spawning areas and times are estimated from age-specific growth data and current patterns, which are projected backwards in time using estimates of fish age, growth, and estuarine hydrography (Holt et al. 1985; Peters and McMichael 1987; Johnson and Funicelli 1991). This method is inefficient because of the great amount of work involved in conducting net surveys, the uncertainty over the identity of species collected at early life stages (Daniel and Graves 1994), the extensive knowledge of estuarine hydrography required, and the spatial extrapolation involved. Another method that has been used extensively to locate spawning adults of many species is to capture fishes with nets and determine the gonadal condition (Merriner 1976; Brown-Peterson et al. 1988; Murphy and Taylor 1990; Lowerre-Barbieri et al. 1996). This method requires the capture of spawning fish and the determination of reproductive stage via gonad dissection and histological sampling; the method also depends on the previous knowledge of spawning locations so that nets can be deployed in appropriate areas. Furthermore, because fish often migrate before spawning, sites where adults with ripe gonads are captured may differ from the ultimate spawning locations; thus, use of ripe-adult locations can introduce error into spawning habitat location estimates. Although both traditional methods will provide data on spawning locations and seasons, they are time consuming and do not lend themselves to easy use by fishery managers, who must often assess population status quickly and make area and season closure decisions rapidly.

In contrast, passive acoustic methods are rapid, inexpensive, noninvasive (one does not have to kill or capture fish to identify them), and useful in lowvisibility waters; furthermore, multiple locations can be monitored simultaneously, and gear selectivity and net avoidance problems do not exist. The approach is restricted to use on soniferous fishes, like sciaenids and gadids (Hawkins and Rasmussen 1978). There are many commercially and recreationally significant fishery species that make sounds; over 700 species are currently described as soniferous (Kaatz 2002). At least 15 species of soniferous fishes occur in estuaries of the southeastern USA, representing eight families: Ariidae, Batrachoididae, Blenniidae, Carangidae, Gobiidae, Haemulidae, Lutjanidae, Sparidae, and Sciaenidae (Burkenroad 1931; Fish and Mowbray 1970; Myrberg 1981; Mok and Gilmore 1983; Gilmore 2003).

\section{Fishery Significance of the Sciaenidae}

Sciaenid fisheries are commercially and recreationally important worldwide, including North Carolina and the USA in general. In North Carolina, three sciaenid species dominate the commercial and recreational fisheries: red drum Sciaenops ocellatus, spotted seatrout Cynoscion nebulosus, and weakfish C. regalis. In 1992-2005, these three species contributed over US\$2,000,000 annually to the commercial fisheries of North Carolina; this total was only $\$ 703,347$ in 2005 because of declining catches (North Carolina Division of Marine Fisheries [NCDMF] 2005). The recreational harvest is almost certainly worth more when the cost of fishing is assessed in terms of contingent value. A fourth species, silver perch Bairdiella chrysoura, although not the target of a significant commercial or recreational fishery, is ecologically important in that it dominates some coastal fish surveys and contributes $32 \%$ to the diets of bottlenose dolphins Tursiops truncatus (Barros and Odell 1990). All of these fishes are sound producing and produce spawning-related sounds (Guest and Lasswell 1978; Mok and Gilmore 1983; Luczkovich et al. 1999; Gilmore 2003); thus, passive acoustic methods can be used to study them and locate their spawning areas.

Because of the economic importance of these sciaenid fisheries, fishery management agencies require knowledge of spawning locations to regulate fishing effort, protect essential spawning habitat, and monitor spawning stock biomass fluctuations. Stock assessments of red drum (Vaughan and Carmichael 2002) suggest that the stock, which had been declining along the U.S. Atlantic coast from 1980 to 1992, has been slowly recovering in response to a series of management actions (total harvest bans, commercial quotas, recreational bag limits, and size or slot limits). Red drum are considered overharvested along the southeastern coast of the USA, as of the recent assessment. Their harvest has been banned in the Exclusive Economic Zone (federal waters extending 5.6-370.0 $\mathrm{km}$ from the coastline) since 1980 , but more recently an intensive recreational fishery has developed in estuarine areas (90\% of the total catch) during the spawning season (Vaughan and Carmichael 2000, 2002). The population currently has a spawning potential ratio of $18 \%$, which is substantially below the desirable level of $40 \%$. Spawning area closures 
during the spawning season have been suggested as a possible management option (Daniels 2001). Both red drum and weakfish are prone to dramatic population fluctuations, and the long-term catch data indicate that populations of both species are in decline. Weakfish stocks declined during the late 1980s and early 1990s (Vaughan et al. 1991) and today are considered overfished. The EFH requirement of the Magnuson Fishery Conservation Act mandates the conservation and monitoring of important habitats, such as spawning areas.

\section{Passive Acoustic Surveys of Sciaenid Spawning Areas}

It has been known for a long time that sciaenid fishes produce sound (Tower 1908; Burkenroad 1931). Their sounds are used in communication during reproduction and aggressive encounters and as disturbance calls (Fish and Mowbray 1970; Guest and Lasswell 1978; Connaughton and Taylor 1996; Gilmore 2003). Worldwide, there are over 280 species of sciaenids and most of them produce sounds, although only a few species' sounds have been thoroughly documented (Fish and Mowbray 1970).

Sciaenid spawning areas have been identified using hydrophone surveys in the past (Mok and Gilmore 1983; Saucier and Baltz 1993; Saucier et al. 1992; Gilmore 2003; Roumillat and Brouwer 2004); this passive acoustic method is becoming routine and is often required by fishery management plans. This is because a hydrophone-assisted acoustic survey of spawning sciaenids is a more expedient way to delineate discrete spawning sites than traditional net capture and fishery-dependent methods.

We focused on applying the passive acoustic method to identify spawning areas of four sciaenid species (red drum, weakfish, spotted seatrout, and silver perch) in North Carolina's Pamlico Sound. We previously demonstrated that the intensity of sciaenid sound production is correlated with sciaenid-type egg production (Luczkovich et al. 1999). Here, we discuss use of an automated passive acoustic sampling device (sonobuoy; Luczkovich et al. 2000) to describe the spatial and temporal distribution of sound production in Pamlico Sound. The goals of this paper were to (1) describe the automated sonobuoys and passive acoustic survey protocol, (2) present spawning habitat data for areas in Pamlico Sound, (3) describe the captive and field recordings of the four sciaenids, and (4) examine the temporal and spatial distribution of each species' sounds. Ultimately, we present spawning habitat maps based on passive acoustic surveys for these ecologically, commercially, and recreationally important species.

\section{Methods}

Study areas.-Based on our previous mobile hydrophone surveys (Luczkovich et al. 1999), we selected two areas for detailed mapping of spawning locations. These areas were Ocracoke Inlet on the eastern side of the Pamlico Sound and the Bay RiverJones Bay area on the western side of the sound (Figure 1). We established sonobuoy stations within these areas to create detailed spawning habitat maps for the four sciaenids. These two areas showed evidence of spawning activity by each species in preliminary mobile hydrophone and ichthyoplankton surveys (presence of sciaenid eggs and sound production).

Captive fish and mobile hydrophone recording.Fish were caught by hook-and-line methods and placed in aerated seawater transport tanks. They were taken to the Pamlico Aquaculture Field Laboratory, Aurora, or to the East Carolina University Department of Biology, Greenville, and held in tanks for recording purposes. Most collected fish emitted calls upon first capture; recordings were made immediately after capture in air or in seawater (in a portable floating net-pen or a cooler). We recognize that captive recordings in such conditions may not produce sounds that are characteristic of free-ranging individuals and that there may be tank echo effects (Parvulescu 1967; Akamatsu et al. 2002), reduced amplitude, and altered patterns of calling (i.e., distress calls are made rather than spawning calls). Underwater recordings of captive weakfish and red drum were made using an InterOcean Acoustic Listening and Calibration System (Model 902; frequency range $=20-10,000 \mathrm{~Hz}$; sensitivity $=$ $-100 \mathrm{~dB}$ referenced to [re] $1 \mathrm{~V} / \mu \mathrm{Pa})$, consisting of an InterOcean hydrophone (Model T-902; sensitivity = $-195 \mathrm{~dB}$ re $1 \mathrm{~V} / \mu \mathrm{Pa}$ ) connected to an amplifier (gain adjustable from 15 to $95 \mathrm{~dB}$ in $10-\mathrm{dB}$ increments, plus vernier adjustment). The amplifier output was recorded with a portable digital audio tape (DAT) recorder (Sony TCD-D8; frequency range $=20-22,000 \mathrm{~Hz} \pm 1$ $\mathrm{dB})$ with 16 bits of resolution and a sampling rate of 48 $\mathrm{kHz}$. Air recordings of silver perch and spotted seatrout were made using an electret condenser microphone (Panasonic; Model WM-54B; frequency range $=20$ $16,000 \mathrm{~Hz} \pm 2 \mathrm{~dB}$; sensitivity $=-164 \mathrm{~dB}$ re $1 \mathrm{~V} / \mu \mathrm{Pa}$ ) and amplifier (gain adjustable from 0 to $40 \mathrm{~dB}$ in 20$\mathrm{dB}$ increments, plus vernier adjustment) and recorded to the same DAT recorder.

By listening to recordings and using spectrographic analyses to classify unknown recordings when in doubt (Sprague et al. 2000), we were able to easily discriminate among calls of the four sciaenids and other known fishes. The same mobile hydrophonerecording system was used to record fish sounds in the 


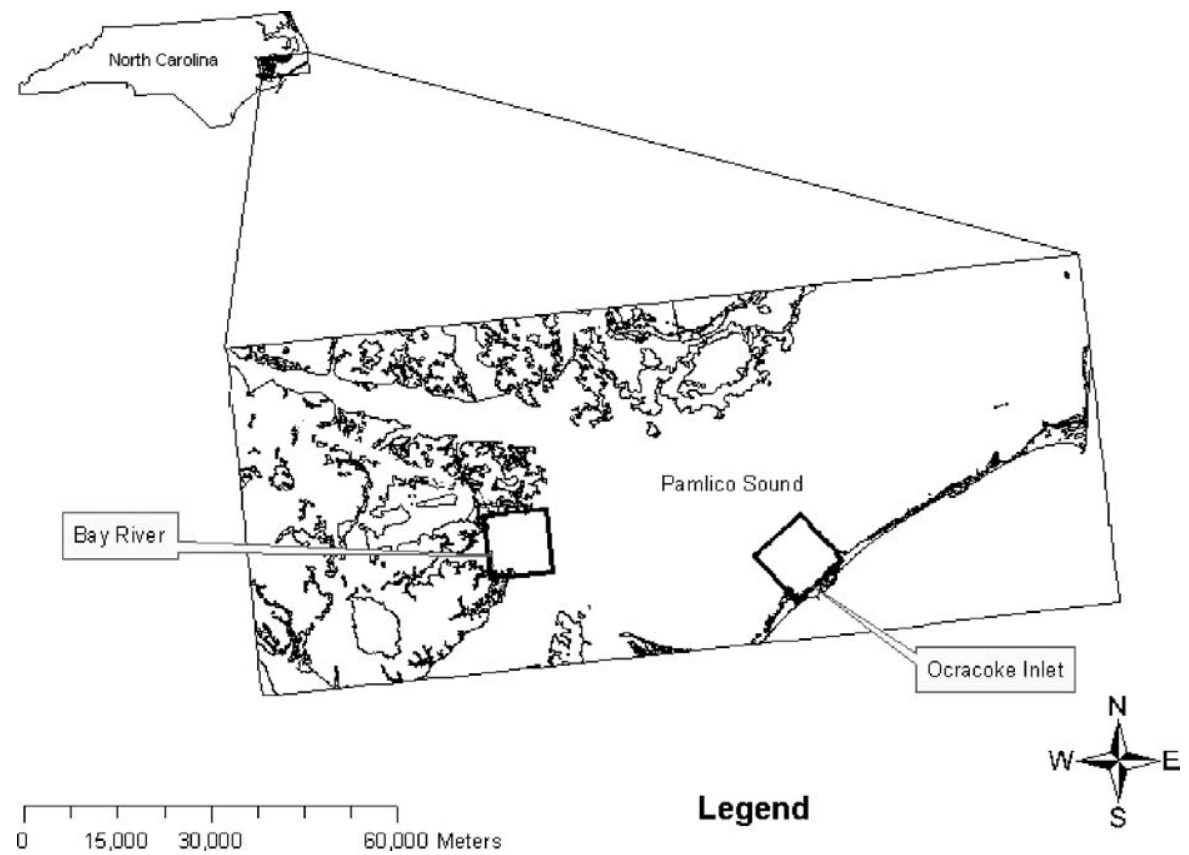

Figure 1.- Map of the study area in Pamlico Sound, North Carolina, showing two sonobuoy sampling grid locations at Ocracoke Inlet and Bay River, where sounds of four sciaenid species were studied.

field at various locations where we deployed sonobuoys to allow comparisons between mobile and sonobuoy hydrophone-recording systems. Additionally, we recorded water temperature at the surface and bottom using a Yellow Springs Instruments (YSI) water quality meter (Model 85) and analyzed the pulse repetition rate for each fish species at different water temperatures that occurred during the field surveys.

Sonobuoy surveys.-Ten sonobuoys were constructed to record sounds indicative of fish spawning (Figure 2). Internally, a sonobuoy consisted of an electronic timing circuit, a standard audiocassette tape recorder with automatic gain control disabled (Sony; Model TCM 313), a power supply (6 V; 4 C-cell batteries), and a "talking" clock (Radio Shack; Model 63-910) set to local time, which announced the time and recorded it to tape at the start of each 90-s recording (Figure 2A). Externally, the sonobuoy was constructed of a $76.2-\mathrm{cm}$ length of $10.2-\mathrm{cm}$-diameter, schedule-40 polyvinyl chloride plumbing pipe, which acted as a waterproof housing (Figure 2B). A hydrophone (Gulton; Model GLN-9190; frequency range $=30-2,000 \mathrm{~Hz} \pm 3 \mathrm{~dB}$; sensitivity $=-174 \mathrm{~dB}$ re $1 \mathrm{~V} / \mu \mathrm{Pa}$ ) was glued to the outside end cap of the tube and was wired internally to the electronics. The sonobuoy recording system was calibrated by the method of comparison (Urick 1983) via a reference hydrophone (Gunnar Rasmussen; Model 10CS; frequency range $=0.1-25,000 \mathrm{~Hz} \pm 1$
$\mathrm{dB}$; sensitivity $=-211.7 \mathrm{~dB}$ re $1 \mathrm{~V} / \mu \mathrm{Pa}$ ). Within the frequency ranges used by fishes, this hydrophonerecording system was comparable to the mobile hydrophone system described above. After the sonobuoy was deployed, the talking alarm clock started the record timer circuit, initiating the first recording. The time announcement was recorded to the cassette, and a 90-s recording of ambient sounds was made through the hydrophone. The power to the cassette recorder was then shut off while the timer circuit waited for a 30- or 60-min (programmable) interval before restoring power to the cassette recorder to start another 90-s recording. The loop of circuits repeated in this sequence until the cassette tape was full (or the battery was exhausted). In this way, we could extend the recording time of a 45min cassette tape to a sonobuoy sampling duration of either 15 or $24 \mathrm{~h}$. We used 30-min intervals for our standard sonobuoy recordings (called nocturnal sonobuoys because they were deployed in the evening hours), which resulted in a cassette tape recording of 30 sound samples taken over $15 \mathrm{~h}$ (45 min of recorded tape). We used the 60-min interval for certain sonobuoy recordings (called 24-h sonobuoys), which allowed for a full day of sampling and for diurnal patterns of fish sound production to be determined.

Each month during May-September 1998, sonobuoys were deployed at different locations on four consecutive nights within the Ocracoke Inlet and Bay 
A)

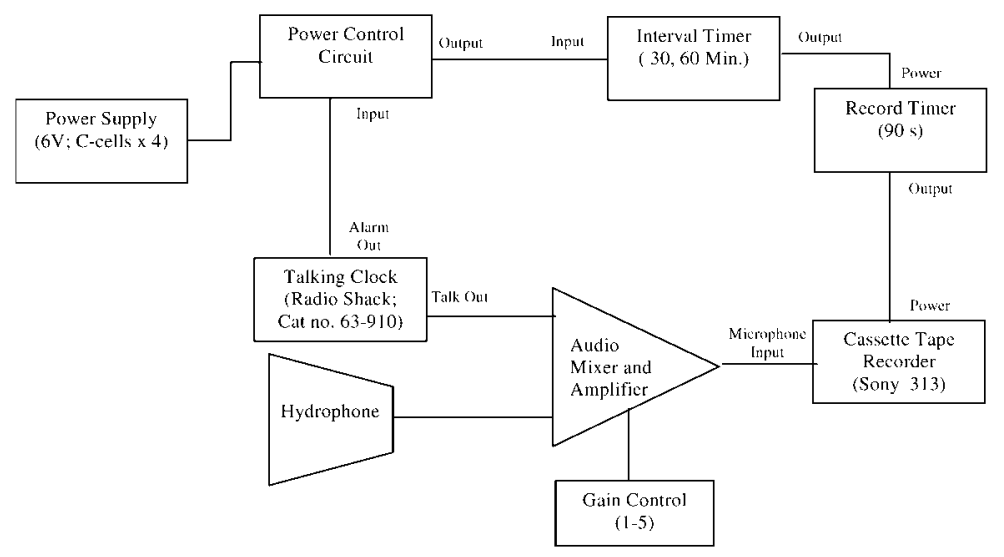

B)

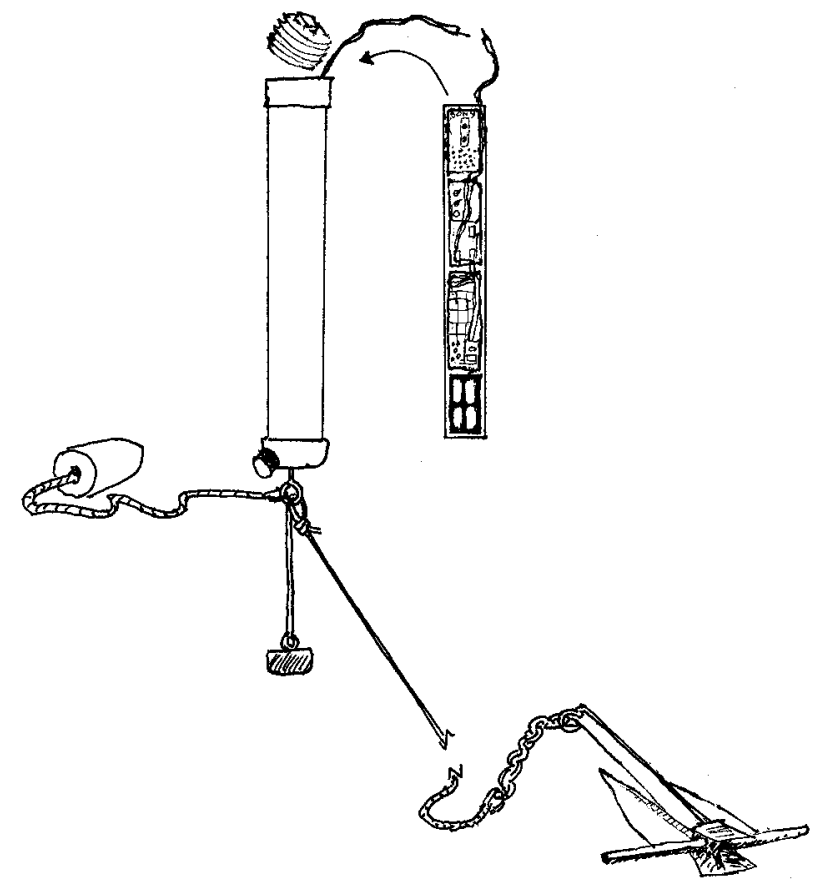

\section{J. LUCZKOVICH 99}

FIGURE 2.-(A) Schematic of an electronic circuit in a sonobuoy used to record sounds of four sciaenid species in Pamlico Sound, North Carolina, and (B) sonobuoy housing diagram, illustrating the hydrophone attached to the outside, the aluminum frame insert (contains timing circuit, tape recorder, and battery supply), and the float and anchor set-up. 
River study areas; the Ocracoke Inlet locations were completed in the first week of each month, and the Bay River locations were surveyed in the third week of each month. During May 1998, sonobuoys were deployed only at Ocracoke Inlet; these were nocturnal sonobuoy test deployments set at 7.5-, 15.0-, and 30.0-min intervals. Most of these sonobuoys recorded sounds, which were resampled at 30-min intervals for the analyses. At the time of each deployment, the depth (from the vessel's fathometer), location (latitude and longitude from a differential Global Positioning System receiver), and water quality variables at the surface and bottom (temperature, ${ }^{\circ} \mathrm{C}$; salinity, \%o; dissolved oxygen, $\mathrm{mg} / \mathrm{L}$; YSI Model $85 \mathrm{~m}$ ) were measured and recorded. The sonobuoys were typically set to begin recording at 1800 hours local (daylight savings) time and were placed at the sampling locations between 1400 and 1600 hours in the afternoon. The next day, the sonobuoys were collected, the tapes were removed for later analysis, and the sonobuoys were reset in new locations. Beginning in June 1998, one 24-h sonobuoy was set at a fixed location in each study area and reset each sampling day, and eight nocturnal sonobuoys were deployed at random positions within the $100-\mathrm{km}^{2}$ sampling region of each study area. A stratified random sampling design was employed: four of the nocturnal sonobuoys were placed in shallow water (1-3 m) and four were placed in deep water (3-9 m) on each sampling night. Thus, we deployed sonobuoys in 16 deep locations and 16 shallow locations within each study area each month. During each month of sonobuoy deployment, a set of random longitude and latitude positions within a $100-\mathrm{km}^{2}$ region was generated for each study area. If a location was deemed unsuitable for sonobuoy deployment $(<1 \mathrm{~m}$ or on a sand bar), then a new position nearby $(<200 \mathrm{~m})$ was selected instead. This ad hoc changing of random positions in the field occasionally resulted in placement of the sonobuoys outside the $100-\mathrm{km}^{2}$ regions.

An experienced fish sound analyst, trained to identify each target species and other soniferous species that occurred in the study area, listened to each sonobuoy tape and scored the tape according to a drumming index (DI). Before scoring the DI for each segment of recorded tape, the analyst consulted with the authors to make certain of the identification of each sound and used spectral analysis to classify sounds when necessary (described below). This qualitative DI, based on a similar index developed for frogs (Heyer et al. 1994; Bridges and Dorcas 2000) and weakfish (Connaughton and Taylor 1995), ranged from 0 to 3 and represented the frequency of occurrence with which a species was detected on a segment of a sonobuoy recording. For each 90 -s audio sample on a sonobuoy recording, the analyst assigned a drumming value for a species of fish according to the following relative scale: (0) not heard; (1) drumming heard infrequently; (2) drumming heard frequently; and (3) continuous drumming indicative of aggregation chorusing. At the end of each night's sonobuoy recording, the DIs for all 90-s recordings were added to obtain a summed nightly DI (SNDI) for each species at that station. These SNDIs were used in statistical analyses and displayed on maps of the sonobuoy locations to visually display the data.

Acoustic and spectrographic analyses.-In situ (sonobuoys or mobile hydrophone-DAT recorder) and captive recordings were used to identify species, estimate pulse repetition rates, and measure dominant frequencies via oscillograms, spectrograms, and average power spectra. Such analyses were done as needed during tape analysis to identify unknown sounds and train tape analysts, and examples are provided here for illustration. Analog sonobuoy tapes were digitized using a Marantz Professional CD recorder (CDR300) at $44.1 \mathrm{kHz}$, and DAT tapes were down-sampled to 24 $\mathrm{kHz}$ using a National Instruments analog-to-digital board (NB-2150F) with antialiasing filters on a Power Macintosh computer. A high-pass $(>60-\mathrm{Hz})$ filter was applied to the recordings to remove noise associated with $\mathrm{AC}$ electricity in the laboratory and vessel noise in the field. Recordings from nature with clear signals from individual fish (rather than multiple overlapping calls from many fishes) were selected for pulse repetition rate and dominant frequency analyses. Pulse repetition rate $(\mathrm{Hz})$ was defined as the number of pulses occurring in a sequence of pulses (pulse train) in the call of an individual fish, divided by the pulse train duration (s). This analysis was performed using the software packages Raven 1.2 (Bioacoustics Research Program, Ornithology Laboratory, Cornell University, Ithaca, New York) for sonobuoy recordings and LabView 5.0 (National Instruments Corp., Austin, Texas) for DAT recordings. Oscillograms and spectrograms were produced from these digital recordings using MATLAB 7.04 (MathWorks, Inc., Natick, Massachusetts). Oscillograms (waveforms) of each sound recording were plotted as relative pressure measured at the hydrophone. We used the "specgram" procedure in the Signal Processing Toolbox of MATLAB to calculate spectrograms based on a 1,024-point fast Fourier transform (FFT) and a Hanning window. The frequency resolution, determined by the sampling frequency and number of points in the FFTs in each power spectrum, is $23.4 \mathrm{~Hz}$. The relative power spectral density (PSD; $\mathrm{dB}$ ) in each spectrogram is given such that the background level (the lightest region) was $30-40 \mathrm{~dB}$ below the 
maximum sound level recorded. In each of our spectrograms, only the frequencies from 0 to 6,000 $\mathrm{Hz}$ are shown. To determine the dominant frequencies precisely, we used an average power spectrum, which averages the sound intensity occurring at different frequencies throughout an entire recording. The dominant frequency is the frequency at which the average PSD is greatest during the period examined, indicated by the peak of the average power spectrum graph of frequency and PSD. An average power spectrum was computed for each recording and plotted using the "Spectrum View" plotting tool in the MATLAB Signal Processing Toolbox based on a Hanning window and a 2,048-point FFT; Welch's PSD averaging method and a sliding, overlapping window of 1,024 points were employed for these calculations. Oscillograms, spectrograms, average power spectra, dominant frequencies, and pulse repetition rates at specific temperatures were compared; by listening to the recordings and conducting these analyses, we were able to identify most of the sounds recorded on the sonobuoys by matching them to captive recordings of known species.

Statistical analysis of sound production and habitat variables.-Box plots were used to display the SNDI at the Ocracoke Inlet and Bay River sites and over the months of sampling. For each group, the horizontal line depicts the median SNDI, the box encloses $50 \%$ of the SNDI values (interquartile range), and the vertical line indicates values equal to 1.5 times the interquartile range. Values occurring outside the vertical lines are shown as asterisks (outside values) or circles (faroutside values; described in SYSTAT 11.0; SYSTAT Software, Inc., Port Richmond, California). A KruskalWallis nonparametric test was used to compare the SNDI at the two sites and between depth strata. The SNDI approximated a normal distribution of continuous numbers. Recordings from individual sonobuoys represented independent monthly samples of sound production at each site and so were considered to be replicate samples. We used this index and associated water quality variables and bottom depth to understand habitat relationships for the four sciaenid species. We used classification and regression tree (CART) analysis (De'ath and Fabricus 2000; implemented in SYSTAT 11.0) as a way of associating sound production (the SNDI, which was the dependent variable) with several explanatory habitat variables: study area $(0=$ Bay River mouth, 1 = Ocracoke Inlet) and depth (m), temperature $\left({ }^{\circ} \mathrm{C}\right)$, salinity $(\%)$, and dissolved oxygen $(\mathrm{mg} / \mathrm{L})$ at the surface and bottom. At each successive step in the analysis, CART splits the data set into two subsets at a cut-point along one of the habitat variables and uses a goodness-of-fit statistic, called the propor- tional reduction in error (PRE), to minimize the sum of the squared deviations of the SNDI within each resulting subset. The PRE is a statistic that indicates the proportion of variance explained, much like $R^{2}$ in regression analysis. By maximizing the differences in summed squared deviations between subsets (or minimizing within subsets), CART splits of the data set into two groups at each step, the most homogeneous set of data in each resulting tree branch. Then each of those groups is split again based on the same approach, up to a limit of seven splits. A CART analysis can identify (1) which habitat variables explain the greatest proportion of variance in SNDI and (2) the cut points of these variables. The analysis produces a tree display, and each branch in the tree shows the cut point that has the greatest PRE and shows the mean SNDI for each group resulting from the split. This analysis can give insight into which habitat variables are most associated with a species' distribution (De'ath and Fabricus 2000) — in this case, the distribution indicated by sound production.

\section{Results \\ Recordings of Fishes in Captivity and in the Wild}

Known species-specific drumming sounds produced by captive sciaenids in North Carolina were DAT recorded to provide a call catalog for the target species. From these sounds, we created spectrograms (sonograms), which are useful in detecting the species in field recordings, even when two or more species are present in an area. We have created a web page (Luczkovich 2007) of fish sounds and spectrograms used in this paper. The sounds recorded from captive fishes were used to identify the sciaenid species in field recordings.

In the oscillogram (Figure 3A) and spectrogram (Figure 3B) of a silver perch (standard length [SL] = $150 \mathrm{~mm}$; recorded in a transport container immediately after capture), one can see seven bursts of sound; these are the characteristic "clucks" (Luczkovich et al. 1999) or "knocks" (Mok and Gilmore 1983; Sprague et al. 2000) made by the silver perch. The echo in this recording, which is visible after each burst of sound, is due to the recording being made inside a container. The bursts occur all within $1 \mathrm{~s}$, which is also characteristic of the silver perch. The sound intensity is dominated by frequencies less than $3,000 \mathrm{~Hz}$; the dominant frequency is less than $1,000 \mathrm{~Hz}$. Fieldrecorded silver perch sounds were similar, as can be observed in the oscillogram (Figure 3C) and spectrogram (Figure 3D) of a recording made at station 11 on 14 July 1997. In this recording, an individual silver perch is knocking, producing six bursts within $1 \mathrm{~s}$. The oscillograms and spectrograms are useful for distin- 
A)

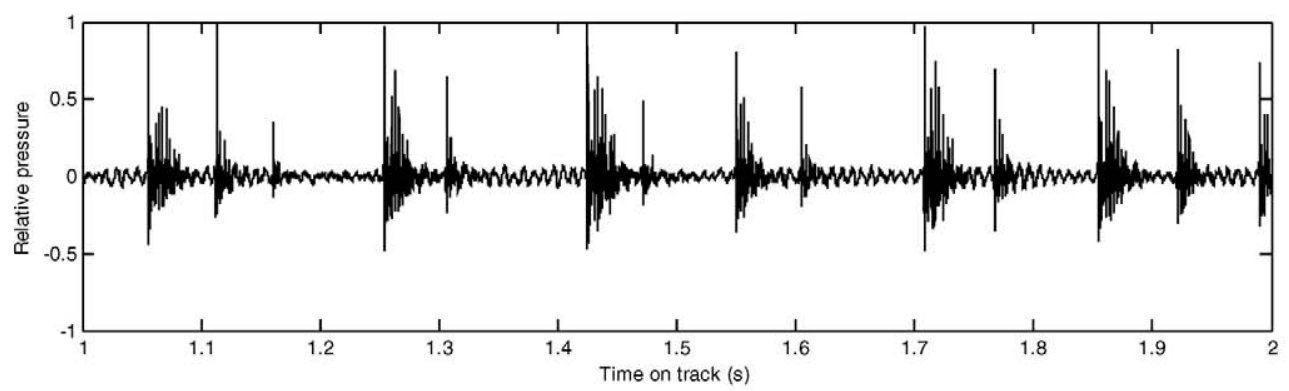

B)

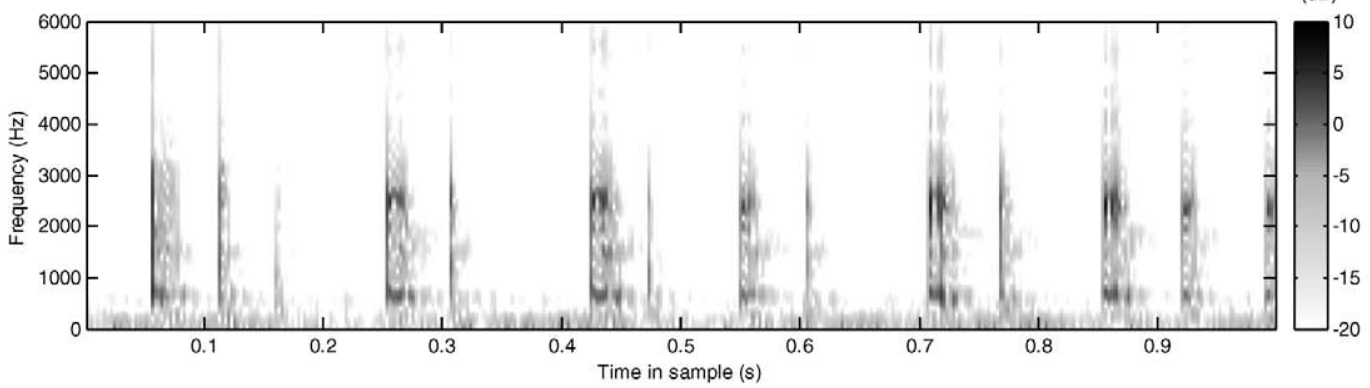

C)

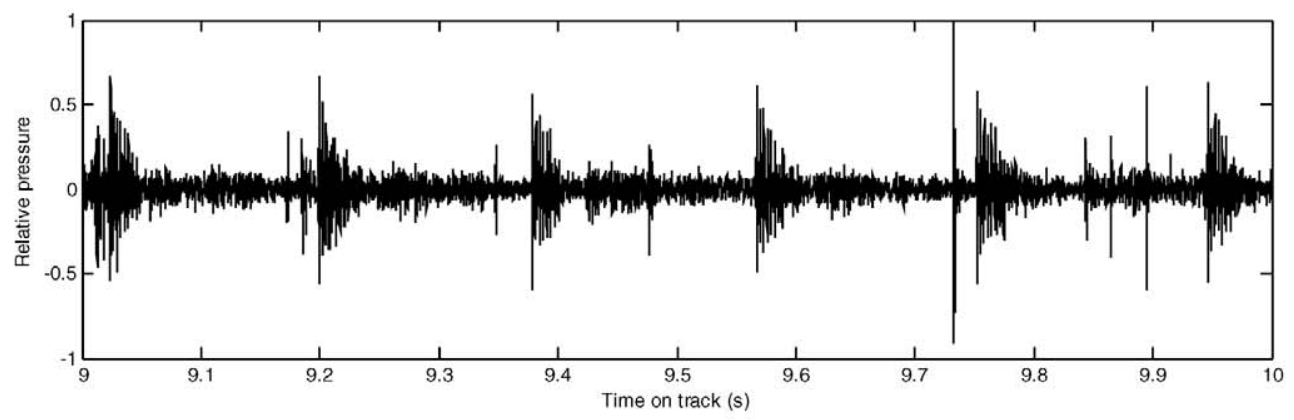

D)

PSD (dB)

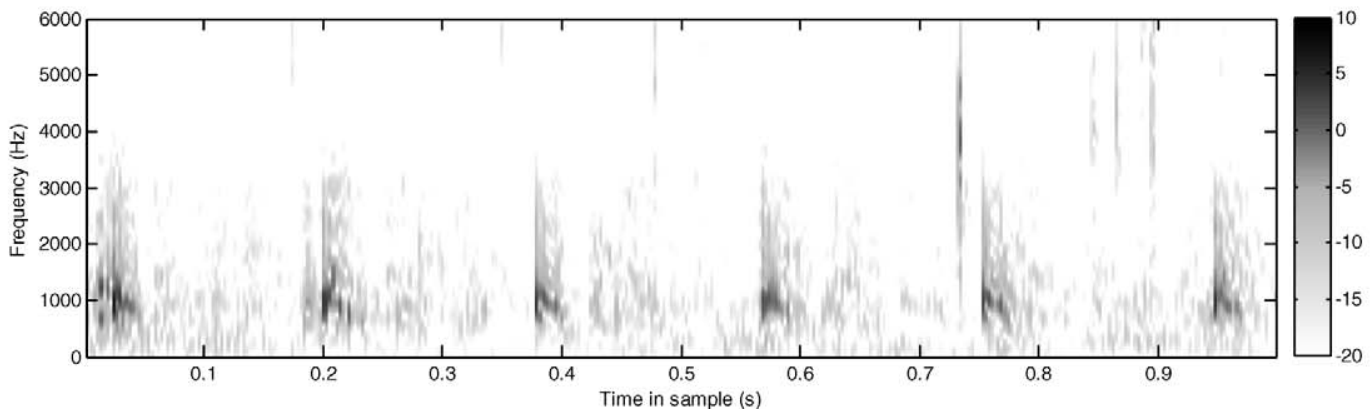

FIGURE 3.-Analyses of silver perch recordings, illustrating knocking or clucking sounds: (A) oscillogram from a captiverecorded fish, $(\mathbf{B})$ spectrogram from the captive fish (PSD = power spectral density), (C) oscillogram from a field-recorded fish in Pamlico Sound, North Carolina, and (D) spectrogram from the field-recorded fish. 
guishing and visualizing the silver perch sound production in field recordings and can easily be compared with captive recordings in spite of the presence of other sound sources in the field. By comparing the spectrograms in Figure 3B and D, one can see the similarity between the captive recording (known species) and field recording (unknown species); this type of sound truthing is essential for identifying species conclusively.

The "purr" of a male weakfish ( $340 \mathrm{~mm} \mathrm{SL}$ ) held in an 89-L cooler filled with seawater was recorded immediately after hook-and-line capture in Teaches Hole during June 1998). As can be seen on the oscillogram (Figure 4A), this purr consists of 15 bursts within a 0.5 -s interval. Each burst has a broad frequency peak and a maximum PSD less than 1,000 $\mathrm{Hz}$ (Figure 4B). In the oscillogram of the field recording of a weakfish (Figure 4C; recorded at station 15 on 14 July 1997), one can see a series of 10 bursts in the 1-s recording, each of which shows the same pattern of pulsing as the captive fish recording in Figure 4A (i.e., a similar pulse repetition rate). However, the field recording is noisier, as reflected in the more variable nature of the oscillogram and the darker color of the spectrogram below $1,000 \mathrm{~Hz}$. These noises are from other weakfish calling in the background during a spawning chorus. The overall similarity in dominant sound frequencies and pulsing patterns is visible in the spectrograms of the captive (Figure 4B) and field recordings (Figure 4D).

A male spotted seatrout captured by hook and line in Roanoke Sound on 8 August 1998 was recorded in air $3 \mathrm{~h}$ after capture. In the recording, the fish makes three long aggregated grunts (LAGs; Mok and Gilmore 1983; Sprague et al. 2000) within $1 \mathrm{~s}$ : the first lasts $0.19 \mathrm{~s}$, the second lasts $0.13 \mathrm{~s}$, and the third lasts $0.11 \mathrm{~s}$ (Figure 5A). The dominant frequencies are again less than $1,000 \mathrm{~Hz}$ (Figure $5 \mathrm{~B}$ ). In an oscillogram of the field recording (Figure 5C), one LAG occurs between 2.9 and $3.2 \mathrm{~s}$; this LAG is also clearly distinguishable in the spectrogram (Figure 5D), even with other spotted seatrout calling in the background.

The characteristic knock produced by a male red drum (within a 24-fish group; mean $\mathrm{SL}=660 \mathrm{~mm}$; range $=500-780 \mathrm{~mm}$ ) was recorded in a tank at the Pamlico Aquaculture Field Laboratory (Figure 6A). The oscillogram and spectrogram show eight knocks, each lasting $0.13 \mathrm{~s}$. The field recording shows four knocks in sequence (Figure 6C), and the dominant frequencies are less than $1,000 \mathrm{~Hz}$ (Figure 6D).

The pulse repetition rate varied significantly with species of fish and with water temperature measured at each sonobuoy location (Table 1). The pulse repetition rate changed with increasing temperature; this rate was low for weakfish $(15.9 \mathrm{~Hz})$ and silver perch $(6.5 \mathrm{~Hz})$ at temperatures less than $23^{\circ} \mathrm{C}(21.5 \mathrm{~Hz})$ but was high at temperatures above $23^{\circ} \mathrm{C}(12.1 \mathrm{~Hz})$. Spotted seatrout and red drum did not call at temperatures below $23^{\circ} \mathrm{C}$, but their pulse repetition rates were different from those of weakfish and silver perch $(18.1 \mathrm{~Hz}$ for spotted seatrout LAGs; $5.1 \mathrm{~Hz}$ for red drum knocks). These species- and temperature-related differences were statistically significant (analysis of variance [ANOVA] for both factors: $P<0.00001$ ), and thus these species can be easily classified based on pulse repetition rate alone.

For sounds of captive- versus field-recorded fish, the dominant frequency was 667 versus $691 \mathrm{~Hz}$ for silver perch, 293 versus $386 \mathrm{~Hz}$ for weakfish, 210 versus 269 $\mathrm{Hz}$ for spotted seatrout, and 152 versus $128 \mathrm{~Hz}$ for red drum (Figure 7A, B). The dominant frequencies of field recordings are similar to those of the captive recordings for each species $(r=0.98)$ and are inversely correlated with the mean size of the species $(r=-0.65)$ recorded in captivity.

\section{Diurnal Pattern of Sound Production}

The 24-h sonobuoy recordings of sound production for each species in each study area indicated that calling activity was largely nocturnal, as denoted by the average DI for each hour during the day (Figure 8). Silver perch were detected most frequently during our study; their calls began just before sunset (2025-2029 hours; Eastern Daylight Time) and continued until just after sunrise (0553-0601 hours), but the DI peaked at 2300 hours. Weakfish followed a similar pattern: sounds began at sunset (when the DI exceeded that of silver perch) and the DI peaked at 2300 hours, but calling ceased at about 0200 hours. Spotted seatrout had the shortest period of drumming activity, which began after sunset (2100 hours), peaked at 2200 hours, and ended at 2300 hours. Red drum began drumming after sunset and the DI peaked at 2200 hours. Red drum sounds were detected during August and peaked in September, but none were apparent during May-July monitoring.

\section{Seasonal Changes in Sound Production}

Seasonal changes in sound production activity of males (an indication of potential spawning activity) can easily be determined from analysis of the sonobuoy recordings, because sonobuoys were deployed with equal sampling intensity on both sides of Pamlico Sound during June-September 1998. In general, silver perch, weakfish, and spotted seatrout could be heard in all months of sonobuoy deployment, whereas red drum were not detected in every month (Figure 9). The sounds recorded on the nocturnal sonobuoy deploy- 
A)

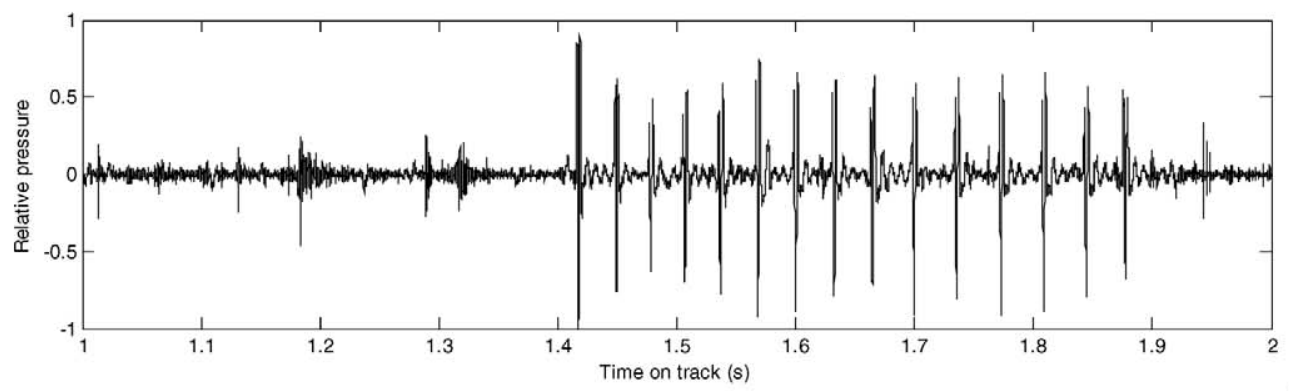

B)

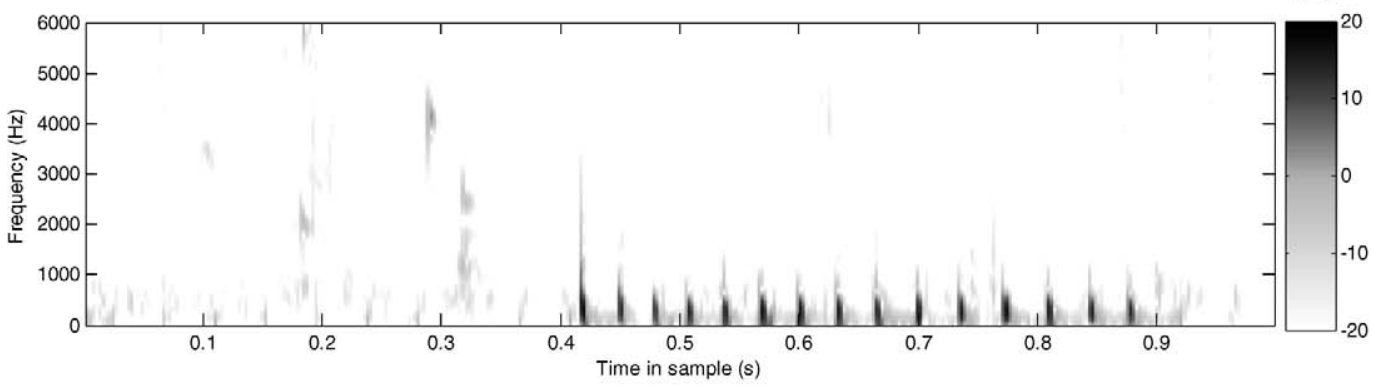

C)

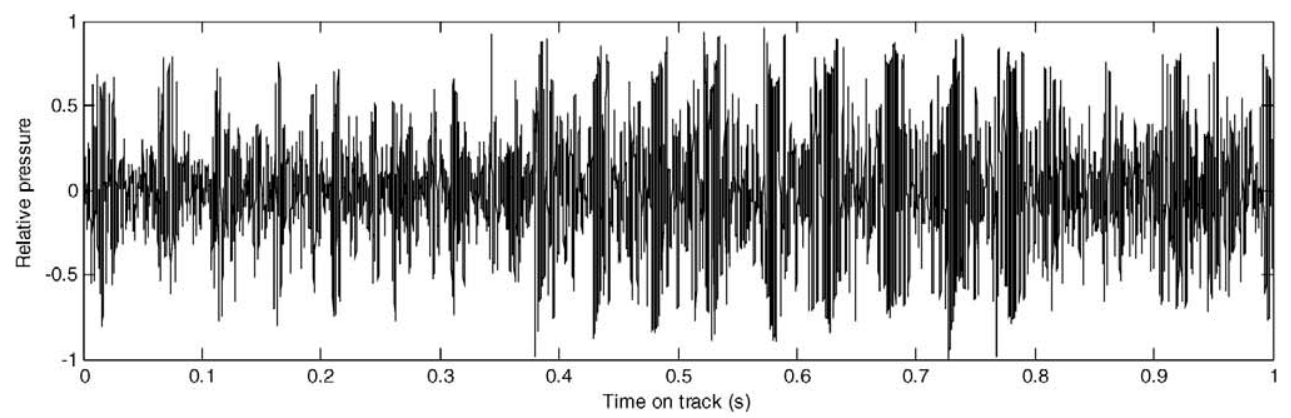

D)

PSD (dB)

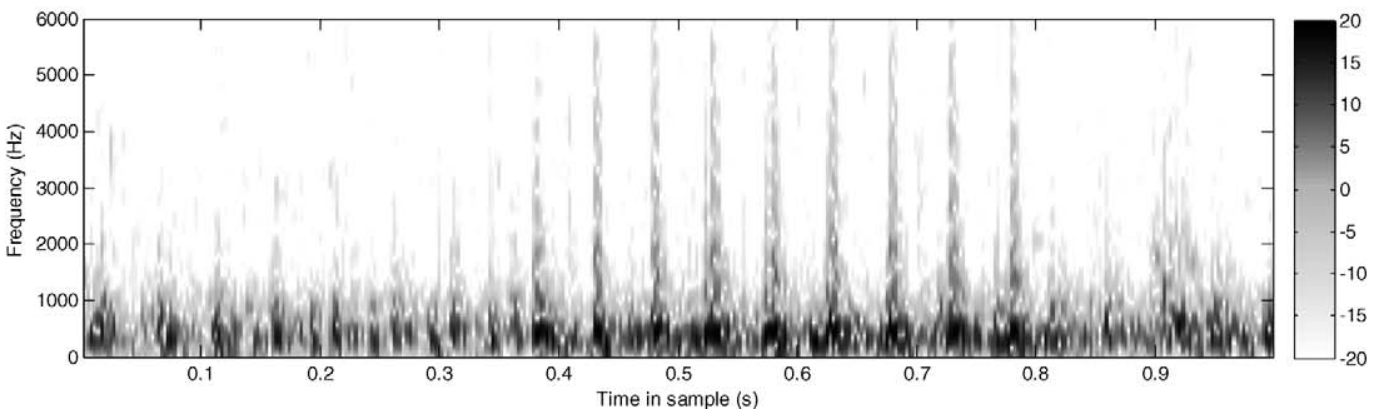

FIGURE 4.-Analyses of weakfish recordings, illustrating purring sounds: (A) oscillogram from a captive-recorded fish, (B) spectrogram from the captive fish (PSD = power spectral density), (C) oscillogram from a field-recorded fish in Pamlico Sound, North Carolina, and (D) spectrogram from the field-recorded fish. 
A)

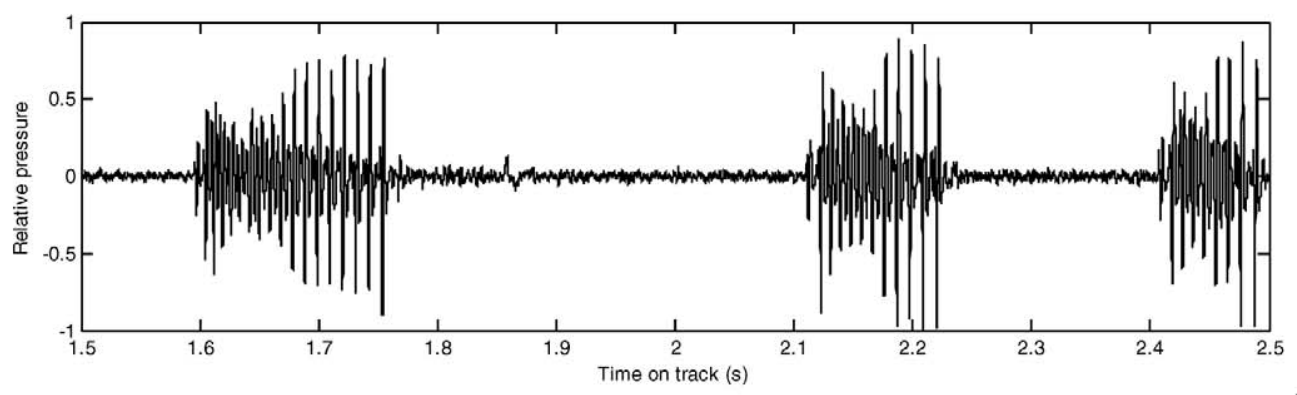

B)

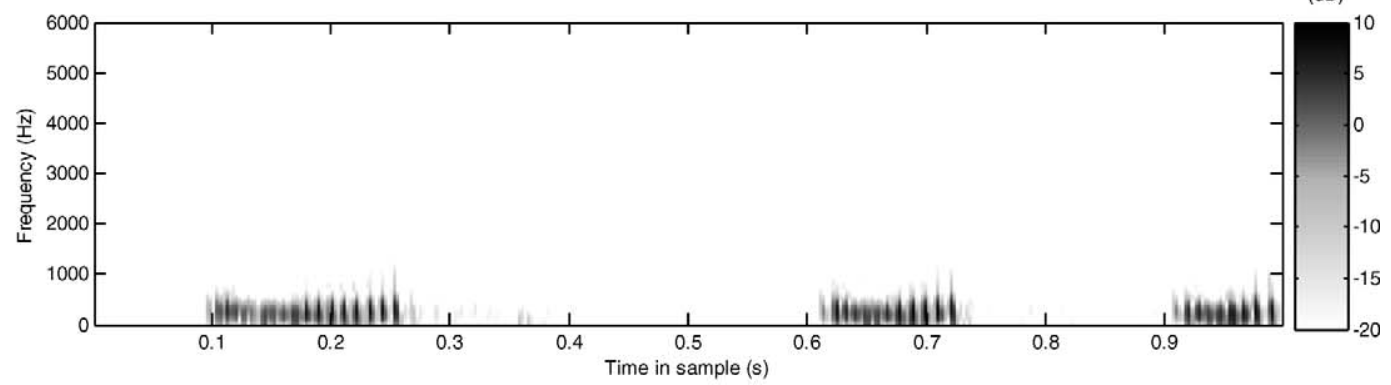

C)

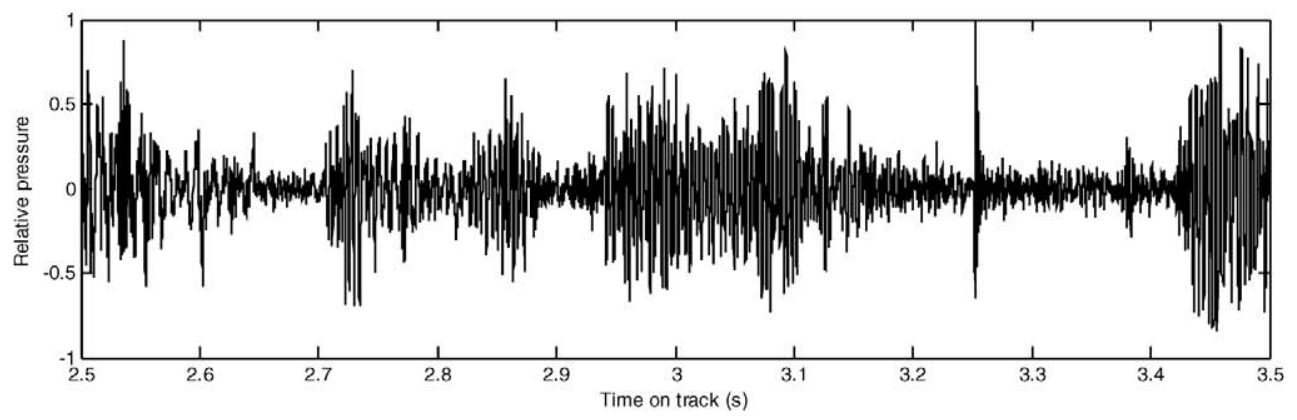

D)

$\operatorname{PSD}(\mathrm{dB})$

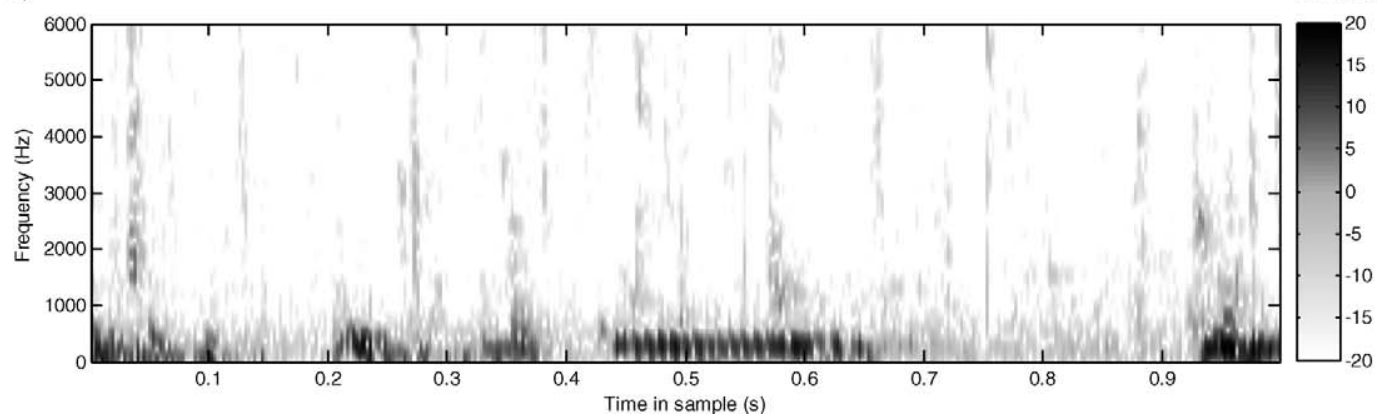

FIGURE 5.-Analyses of spotted seatrout recordings, illustrating long aggregated grunts or burps: (A) oscillogram from a captive-recorded fish, (B) spectrogram from the captive fish (PSD = power spectral density), (C) oscillogram from a fieldrecorded fish in Pamlico Sound, North Carolina, and (D) spectrogram from the field-recorded fish. 
A)

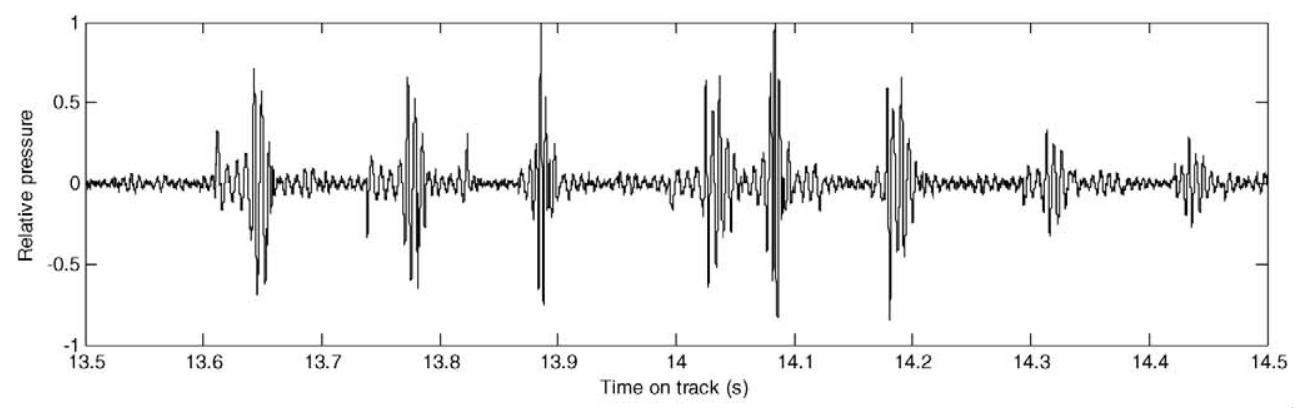

B)

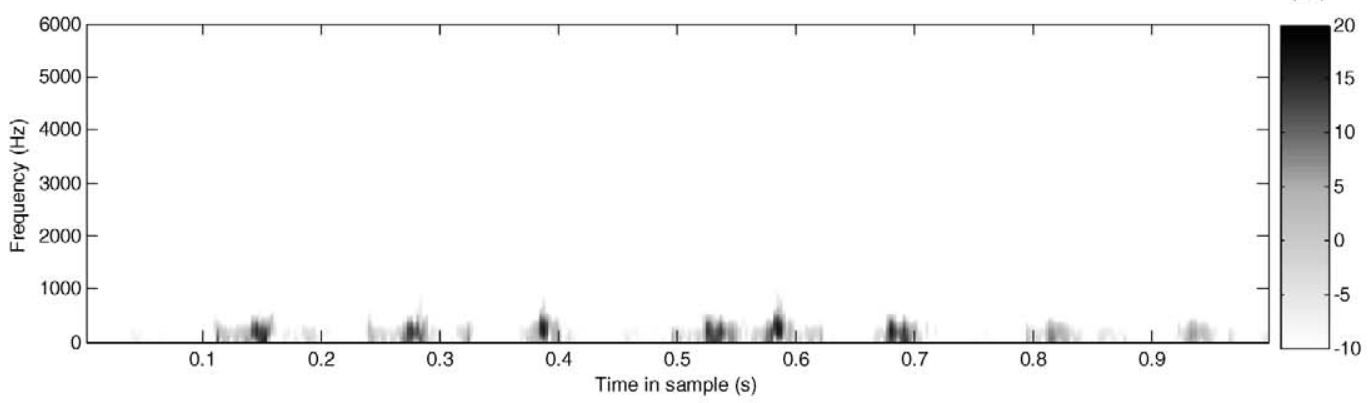

C)

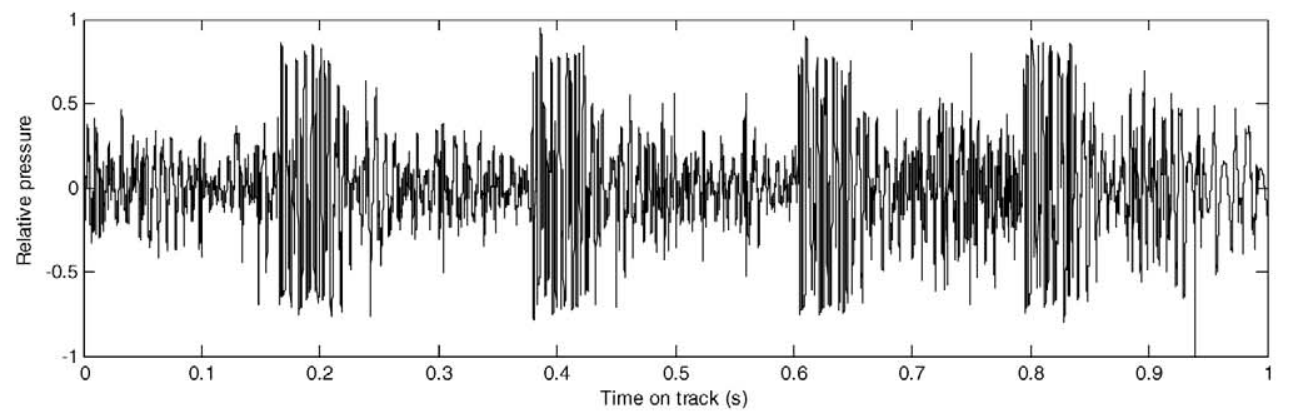

D)

$\operatorname{PSD}(\mathrm{dB})$

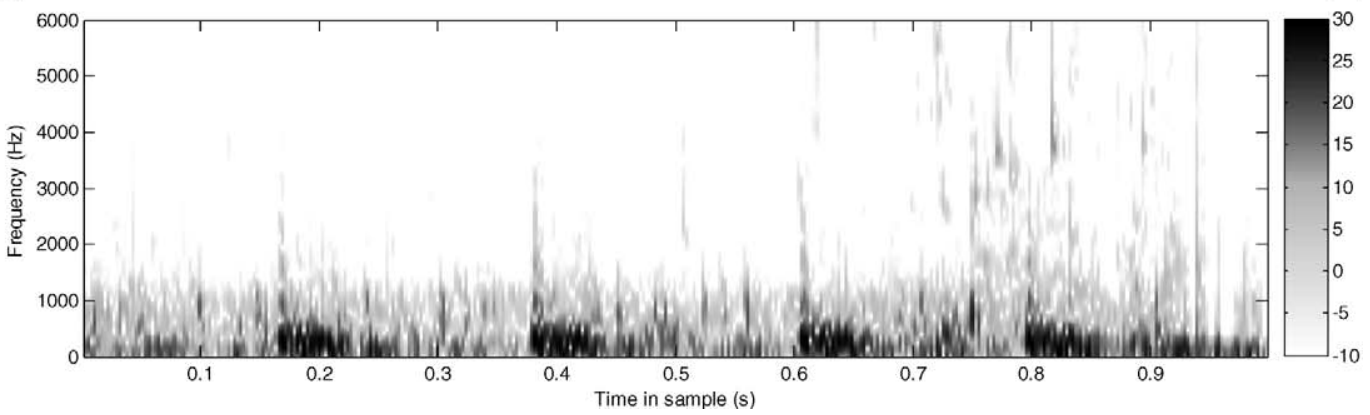

FIGURE 6.-Analyses of red drum recordings, illustrating knocking or drumming sounds: (A) oscillogram from a captiverecorded fish, (B) spectrogram from the captive fish (PSD = power spectral density), (C) oscillogram from a field-recorded fish in Pamlico Sound, North Carolina, and (D) spectrogram from the field-recorded fish. 
TABLE 1.-Pulse repetition rate (PRR) for the calls of four sciaenid species recorded on sonobuoys and with a mobile hydrophone in Pamlico Sound, North Carolina, 1997 and 1998 ( $N=$ number of calls analyzed). Recordings were grouped into two temperature classes corresponding to conditions early in the season $\left(<23^{\circ} \mathrm{C}\right.$; May-June $)$ and later in the season $\left(>23^{\circ} \mathrm{C}\right.$; July-September).

\begin{tabular}{|c|c|c|}
\hline $\begin{array}{l}\text { Species and } \\
\text { temperature }\end{array}$ & Statistic & PRR (Hz) \\
\hline \multicolumn{3}{|l|}{ Silver perch } \\
\hline \multirow[t]{5}{*}{$<23^{\circ} \mathrm{C}$} & Mean & 6.582 \\
\hline & Minimum & 4.227 \\
\hline & Maximum & 8.207 \\
\hline & SD & 0.977 \\
\hline & $N$ & 19 \\
\hline \multirow[t]{5}{*}{$>23^{\circ} \mathrm{C}$} & Mean & 12.103 \\
\hline & Minimum & 12.103 \\
\hline & Maximum & 12.103 \\
\hline & SD & \\
\hline & $N$ & 1 \\
\hline \multicolumn{3}{|l|}{ Weakfish } \\
\hline \multirow[t]{5}{*}{$<23^{\circ} \mathrm{C}$} & Mean & 15.98 \\
\hline & Minimum & 14.995 \\
\hline & Maximum & 18.722 \\
\hline & SD & 1.124 \\
\hline & $N$ & 9 \\
\hline \multirow[t]{5}{*}{$>23^{\circ} \mathrm{C}$} & Mean & 21.491 \\
\hline & Minimum & 19.5 \\
\hline & Maximum & 24.691 \\
\hline & SD & 2.2981 \\
\hline & $N$ & 4 \\
\hline \multicolumn{3}{|l|}{ Spotted seatrout } \\
\hline \multirow[t]{5}{*}{$>23{ }^{\circ} \mathrm{C}$} & Mean & 18.075 \\
\hline & Minimum & 17 \\
\hline & Maximum & 19.934 \\
\hline & SD & 1.616 \\
\hline & $N$ & 3 \\
\hline \multicolumn{3}{|l|}{ Red drum } \\
\hline \multirow[t]{5}{*}{$>23^{\circ} \mathrm{C}$} & Mean & 5.113 \\
\hline & Minimum & 4.566 \\
\hline & Maximum & 5.5 \\
\hline & SD & 0.392 \\
\hline & $N$ & 4 \\
\hline
\end{tabular}

ments were dependent upon the month; weakfish and silver perch had the greatest SNDI in the early part of the survey (May and June), but values declined as autumn approached (September). Spotted seatrout exhibited peak activity in the summer months (JuneAugust) but were also recorded in the spring (May) and autumn (September). Red drum were only recorded in the late summer and autumn (August and September). There was a slight increase in the SNDI for weakfish in August 1998, suggesting the occurrence of a second spawning peak.

\section{Distribution of Sound Production Sites in Pamlico Sound}

We deployed nocturnal sonobuoys at randomly selected locations in Ocracoke Inlet and the Bay River mouth. These sonobuoys recorded the sounds of the fishes present each night over time at a single location and thus were able to detect a species' presence at each sample location if it called during the night. Because these sonobuoys allowed equal sampling effort in both areas simultaneously over the summer in 1998, they represent an index of relative abundance standardized for effort (similar to catch per unit effort in net surveys). The SNDI for silver perch was greater at the Ocracoke Inlet sites than at the Bay River mouth (Kruskal-Wallis: $P<0.00001$; Figure 10). Similarly, more many more weakfish were detected each night in the Ocracoke Inlet than at the Bay River mouth, as evidenced by the greater SNDI (Kruskal-Wallis: $P<$ 0.000001). In contrast, the SNDI indicated more spotted seatrout at Bay River than at Ocracoke Inlet during this same period (Kruskal-Wallis: $P<$ 0.000001). Red drum, which were the least frequently recorded among the four sciaenid species, had very low SNDIs that did not differ between the two areas surveyed (Kruskall-Wallis: $P=0.71$ ). These same patterns are visually apparent in maps of SNDIs at sonobuoy locations superimposed over the two study areas (Figures 11-14). These maps are useful for identifying the EFH for each species.

\section{Sound Production and Essential Fish Habitat}

The sound production varied spatially and temporally, suggesting that the four species did not use estuarine habitats at random but were selecting sites based on the physical characteristics of the location. We examined the habitat conditions that might explain this spatial and temporal distribution using (1) plots of SNDI for each species versus each variable and (2) CART analysis in which the SNDI for each species was the response variable and habitat variables were used as predictors.

We measured several EFH variables (study area location or sound side, and depth, temperature, salinity, and dissolved oxygen at the surface and bottom) at each sonobuoy deployment site and plotted the SNDI for each species against these habitat variables. Depth was an important characteristic of sound production habitat (and presumably spawning habitat) for weakfish and red drum. We deployed the sonobuoys at random within two depth strata: deep $(>3 \mathrm{~m})$ and shallow $(\leq 3 \mathrm{~m})$. The average SNDI for weakfish was greater in the deep stratum (6.9) than in the shallow stratum (3.9; Kruskal-Wallis test: $P=$ $0.03, N=152$ ). This was also true for red drum: the average SNDI was 0.35 in the deep stratum and 0.05 in the shallow stratum $(P=0.003, N=148)$. However, there was no difference in average SNDI for silver perch (deep: 8.1, shallow: 6.4; $P=0.19$ ) or spotted seatrout (deep: 2.8, shallow: $2.9 ; P=0.27$ ). This pattern can be observed in the distribution of SNDI by 
A)

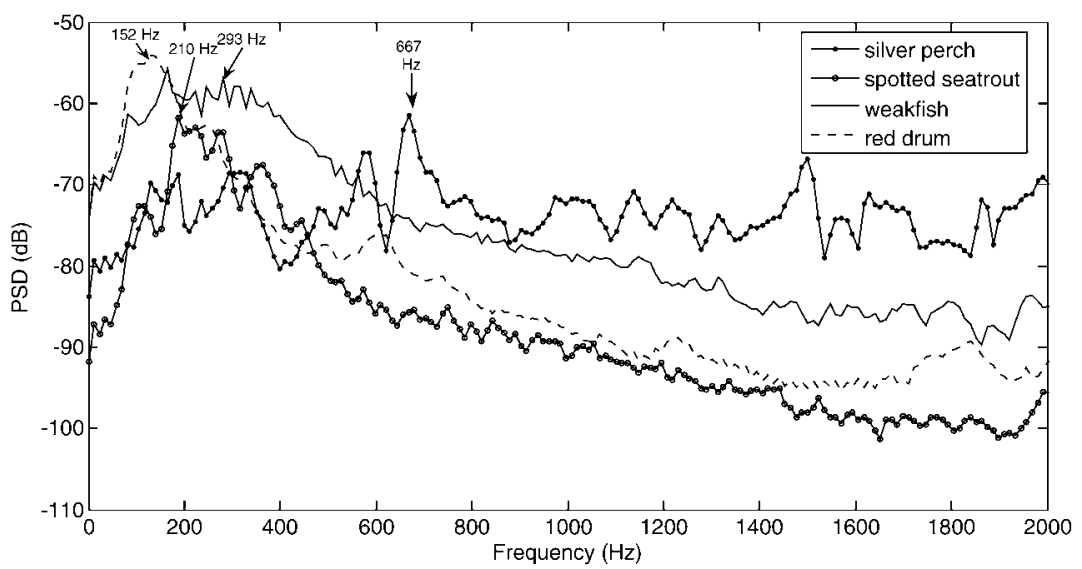

B)

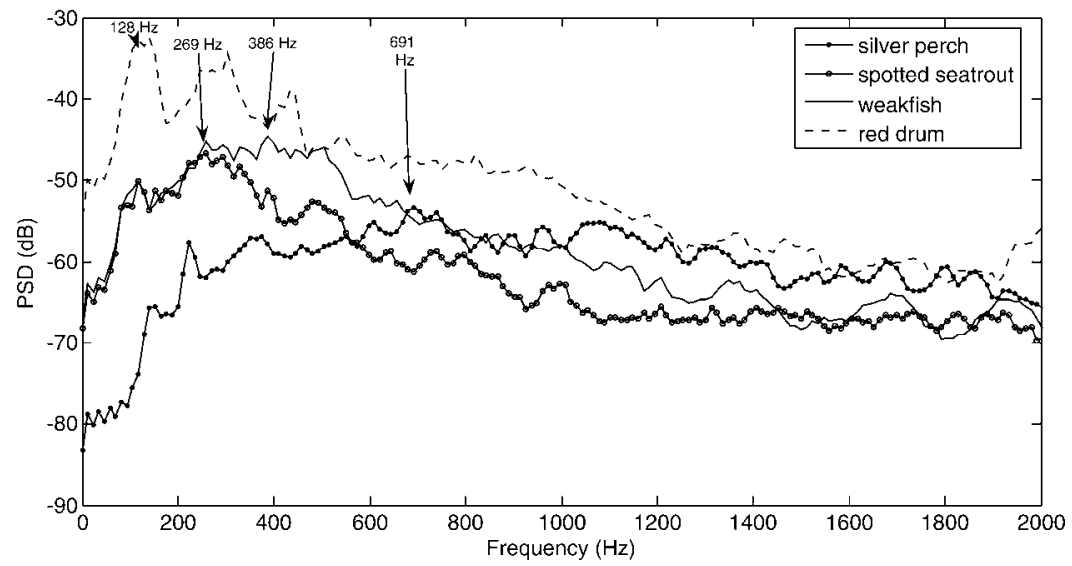

FIGURE 7.-Average power spectral density (PSD) of sounds recorded from silver perch (solid line with shaded circles), spotted seatrout (solid line with open circles), weakfish (solid line), and red drum (dashed line): (A) captive recordings and (B) field recordings made in Pamlico Sound, North Carolina. Arrows indicate the peak or dominant frequency for each species.

depth (Figure 15), which shows that SNDI increases with depth for weakfish and red drum but not for silver perch or spotted seatrout.

The temperature conditions at the bottom of the Pamlico Sound appeared to influence the calling behavior of the fishes, as judged by the SNDIs (Figure 16). The bottom temperatures associated with weakfish calls averaged $25.3^{\circ} \mathrm{C}$ (Table 2 ; range $=17-31^{\circ} \mathrm{C}$ ) and were lower than the bottom temperatures associated with spotted seatrout calls, which averaged $28.0^{\circ} \mathrm{C}$ (Table 2; range $=17-31^{\circ} \mathrm{C}$ ) and had a distribution shift toward higher temperatures (Figure 16). Silver perch were similar to weakfish in the temperatures at which calls were detected $\left(\right.$ Table 2 ; mean $=25.6^{\circ} \mathrm{C}$, range $=$ $15-31^{\circ} \mathrm{C}$ ); indeed, the two species tended to be recorded together on our sonobuoy tapes early in the 


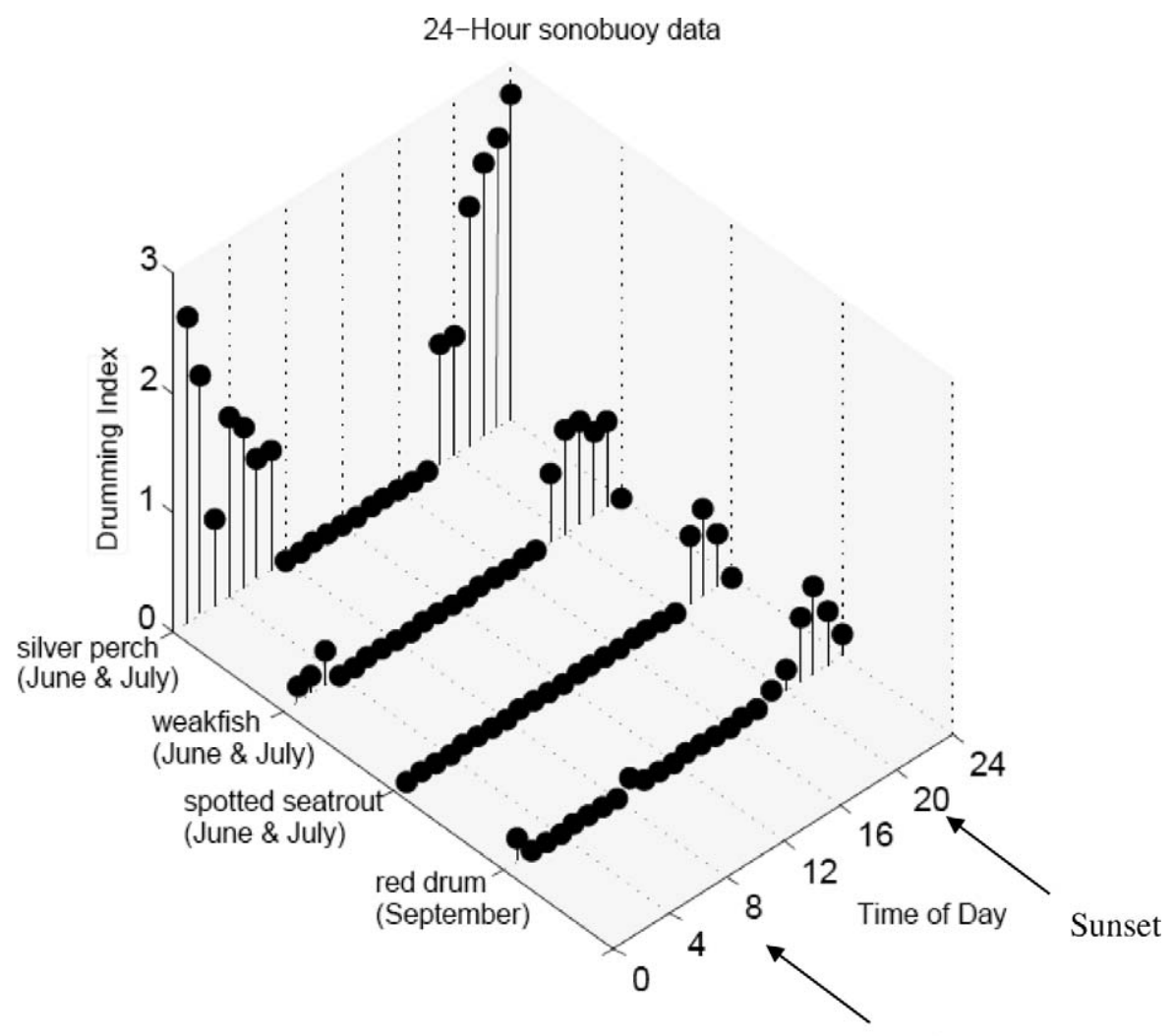

Sunrise

FIGURE 8.-Diel variation in the average drumming index for silver perch, weakfish, spotted seatrout, and red drum recorded by sonobuoys in Pamlico Sound, North Carolina. Weakfish and spotted seatrout data are averages from 2-min recordings by 24-h sonobuoys at Ocracoke Inlet and Bay River (June-July 1998). Red drum data are averages of recordings by normal sonobuoys (30-min intervals between 1800 and 0800 hours) deployed during September 1998 at the two sites.

season (May and June), when bottom water temperatures were still cool but increasing (Figure 16). Red drum, which called only in August and September, tended to call in the warmer waters present at the end of summer; they had a higher temperature distribution similar to that of the spotted seatrout, and the bottom temperature averaged $28.1^{\circ} \mathrm{C}$ (Table 2 ; range $=24.8$ $\left.30.2^{\circ} \mathrm{C}\right)$.

With respect to bottom salinity, weakfish were more commonly heard in higher salinity (Figure 17; Table 2; mean $=15.4 \%$, range $=7.8-28.3 \%$ ) than were spotted seatrout $($ mean $=11.8 \%$, range $=7.1-26.9 \%$ ), but there was a good deal of overlap between these two congeners. However, peak SNDIs of the spotted seatrout occurred in lower salinities than did those of the weakfish. Silver perch tended to co-occur with weakfish in water of similar salinity (mean $=14.0 \%$, range $=7.1-28.3 \%$ ). Red drum generally produced sounds at higher salinities (mean $=14.4 \%$ ) but called over a wide range of salinities (7.8-27.1\%o). In Pamlico
Sound, which generally has low salinity because of its few restricted inlets, these fishes produced sounds at salinities lower than might be expected in other estuaries but at a wide salinity range.

For bottom dissolved oxygen, a critical habitat variable that is of great concern to biologists because of the potential for hypoxia $(<4 \mathrm{mg} / \mathrm{L})$, there was quite a difference in the distribution of SNDI values among the species. Weakfish had a very well-defined lower limit (Table 2; mean $=7.6 \mathrm{mg} / \mathrm{L}$, range $=2.65-10.4$ ), and only a single sonobuoy recorded their calls at dissolved oxygen levels below $4 \mathrm{mg} / \mathrm{L}$ (Figure 18). Spotted seatrout, on the other hand, were recorded at dissolved oxygen levels as low as $0.05 \mathrm{mg} / \mathrm{L}$ (mean = $6.1 \mathrm{mg} / \mathrm{L}$, range $=0.05-9.73 \mathrm{mg} / \mathrm{L}$ ), suggesting that hypoxia did not limit their sound production. Indeed, some of the highest SNDI values occurred at hypoxic $(<4 \mathrm{mg} / \mathrm{L})$ sonobuoy stations. Some fairly high SNDI values were recorded for silver perch in hypoxic bottom waters, although most sonobuoy recordings 

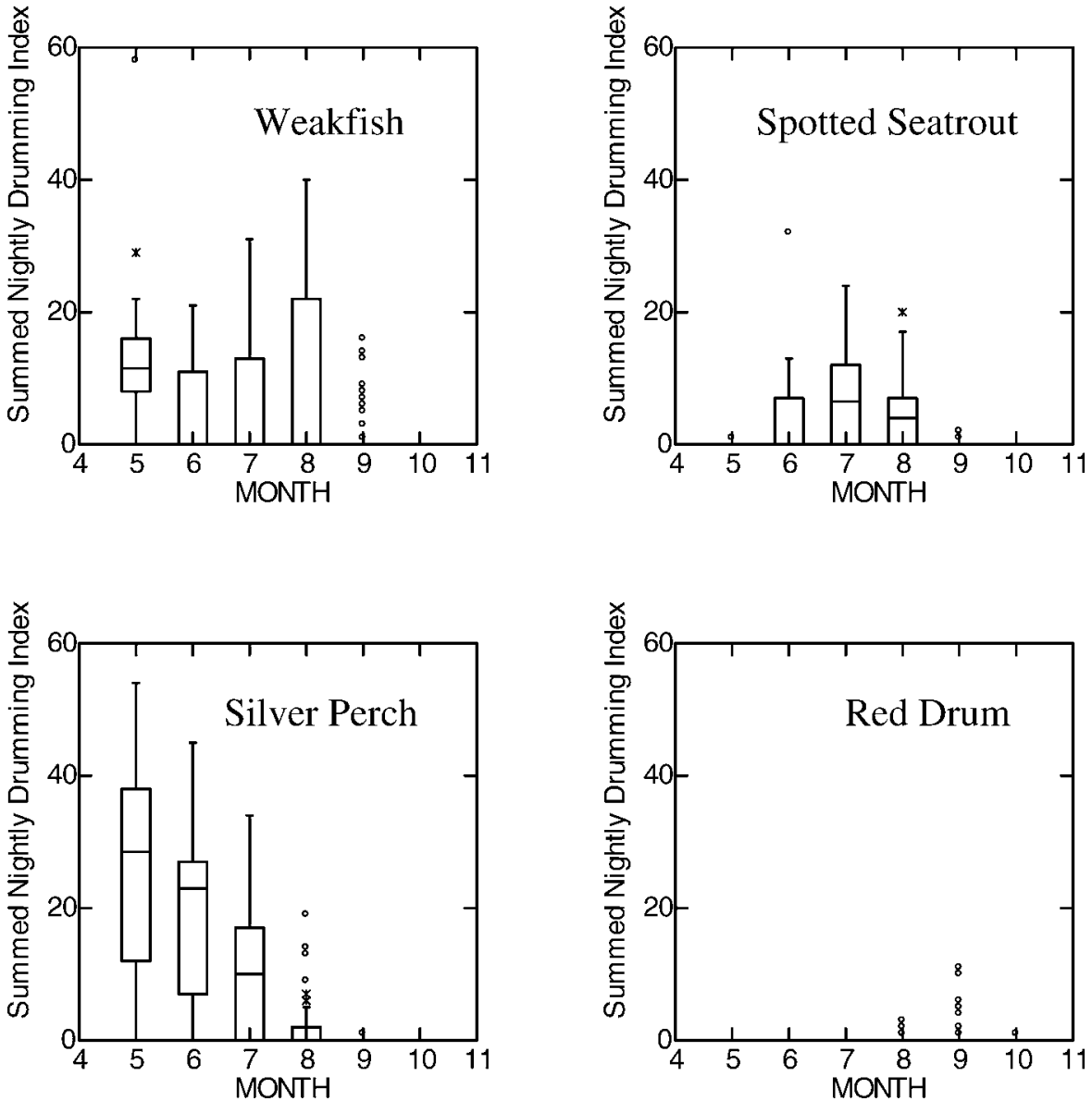

FIGURE 9.-Box plots showing seasonal changes in the summed nightly drumming index for weakfish, silver perch, spotted seatrout, and red drum recorded by sonobuoys in Pamlico Sound, North Carolina (month $5=$ May; month $9=$ September; horizontal line $=$ median; box $=50 \%$ of the data around the median; vertical line $=95 \%$ data around the median; circles and asterisks $=$ individual points).

were from normoxic waters $($ mean $=7.0 \mathrm{mg} / \mathrm{L}$, range $=$ $1.03-10.4 \mathrm{mg} / \mathrm{L}$ ), as was true for red drum (mean $=6.7$ $\mathrm{mg} / \mathrm{L}$, range $=4.5-9.5 \mathrm{mg} / \mathrm{L}$ ).

The CART analysis of SNDIs was used to characterize the critical habitat variables for each species. For weakfish, sound production was most common at Ocracoke Inlet (sound side $=1$, mean SNDI $=13.7, N=95$ sonobuoys, PRE $=0.49)$ or where depth exceeded $2.1 \mathrm{~m}$ (mean SNDI $=16.2, N=73$ sonobuoys, PRE $=0.59$ ), particularly those depths greater than $5.2 \mathrm{~m}(\mathrm{SDNI}=29.1, N=7$ sonobuoys, $\mathrm{PRE}=0.65$; Figure 19A). In contrast, spotted seatrout produced sounds most frequently where surface temperature exceeded $28.0^{\circ} \mathrm{C}$ (mean SNDI $=6.7, N=$ 101 sonobuoys, $\mathrm{PRE}=0.23$ ), in the Bay River study area (sound side $=0$, mean $\mathrm{SNDI}=8.2, N=79$ sonobuoys, $\mathrm{PRE}=0.35$ ), or where surface salinity was greater than 8.1\%o (mean SNDI $=10.6, N=54$ sonobuoys, PRE $=0.49$; Figure 19B). Silver perch produced sounds most frequently in the Ocracoke Inlet (sound side $=1, \mathrm{SNDI}=15.0, N=95$ sonobuoys, $\mathrm{PRE}$ $=0.23$ ), where bottom dissolved oxygen concentration was greater than $7.4 \mathrm{mg} / \mathrm{L}$ (mean SNDI $=21.8, N=57$ sonobuoys, PRE $=0.45$ ), or where bottom temperature was less than $25.8^{\circ} \mathrm{C}$ (mean SNDI $=26.7, N=37$ sonobuoys, $\mathrm{PRE}=0.54$; Figure $19 \mathrm{C}$ ). For red drum, the only significant habitat variable associated with sound production was surface salinity greater than $22.3 \%$ (mean SNDI $=1.7, N=7$ sonobuoys). However, only a small number of sonobuoys recorded red drum, and thus only a low amount of variance was explained (PRE $=0.20$; Figure 19D). The habitat 

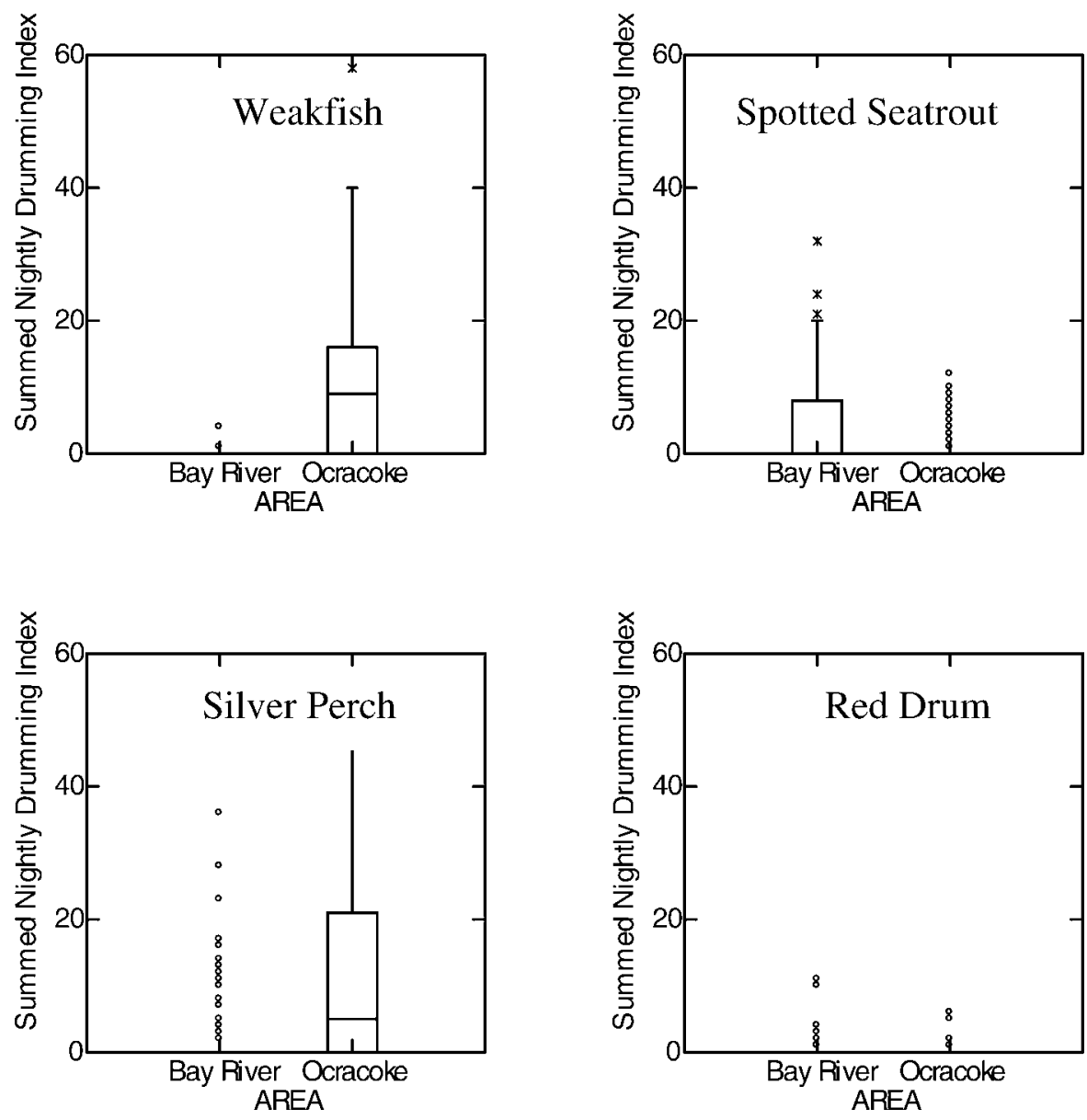

FIGURE 10.-Box plots of the summed nightly drumming index for weakfish, silver perch, spotted seatrout, and red drum recorded by sonobuoys deployed in two areas of Pamlico Sound, North Carolina (Bay River, lower salinity: 10-12\%; Ocracoke Inlet, higher salinity: $15-30 \%$ ), during May-September (horizontal line $=$ median; box $=50 \%$ of the data around the median; vertical line $=95 \%$ data around the median; circles and asterisks $=$ individual points).

conditions listed above occurred at the sites most frequently used for sound production by males of these species, and presumably these were spawning locations as well. These physical habitat conditions, determined via passive acoustic measures, defined the species' spawning habitats in Pamlico Sound.

\section{Discussion}

The passive acoustic survey reported here revealed a great deal about the sound production behavior, habitat use, and spawning activity of weakfish, spotted seatrout, red drum, and silver perch. Sound production has been associated with egg production and spawning in these four species (Mok and Gilmore 1983; Luczkovich et al. 1999; Lowerre-Barbieri et al., 2008 this issue); therefore, we assume that the recorded sounds were spawning-related calls used by males to attract females.
The individual behavior and spatial distribution of the males and females during the spawning events are still poorly described for these species. Sound production associated with spawning is likely to be an advertisement call produced by the males (Connaughton and Taylor 1996) in a manner similar to that used by Atlantic cod Gadus morhua to attract females to group spawning aggregations (Nordeide and Folstad 2000) or by oyster toadfish Opsanus tau to attract females to the territories of individual males (Fine and Thorson 2008, this issue). Additional studies of in situ spawning behavior in these fish are needed to determine the function of sound production in spawning.

The variations in sound production by these four sciaenids were related to time of day and season. Sound production occurred nocturnally, beginning at sunset and lasting in some cases until the next morning (silver 
A)

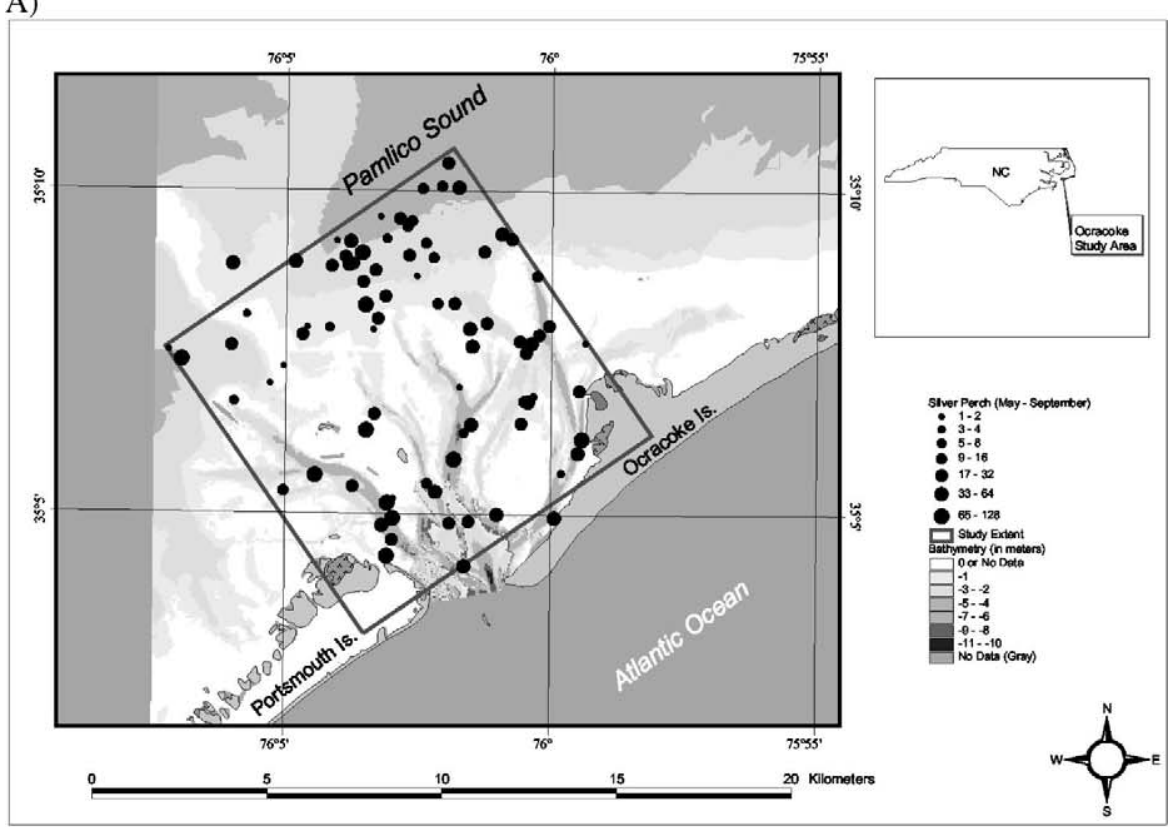

B)

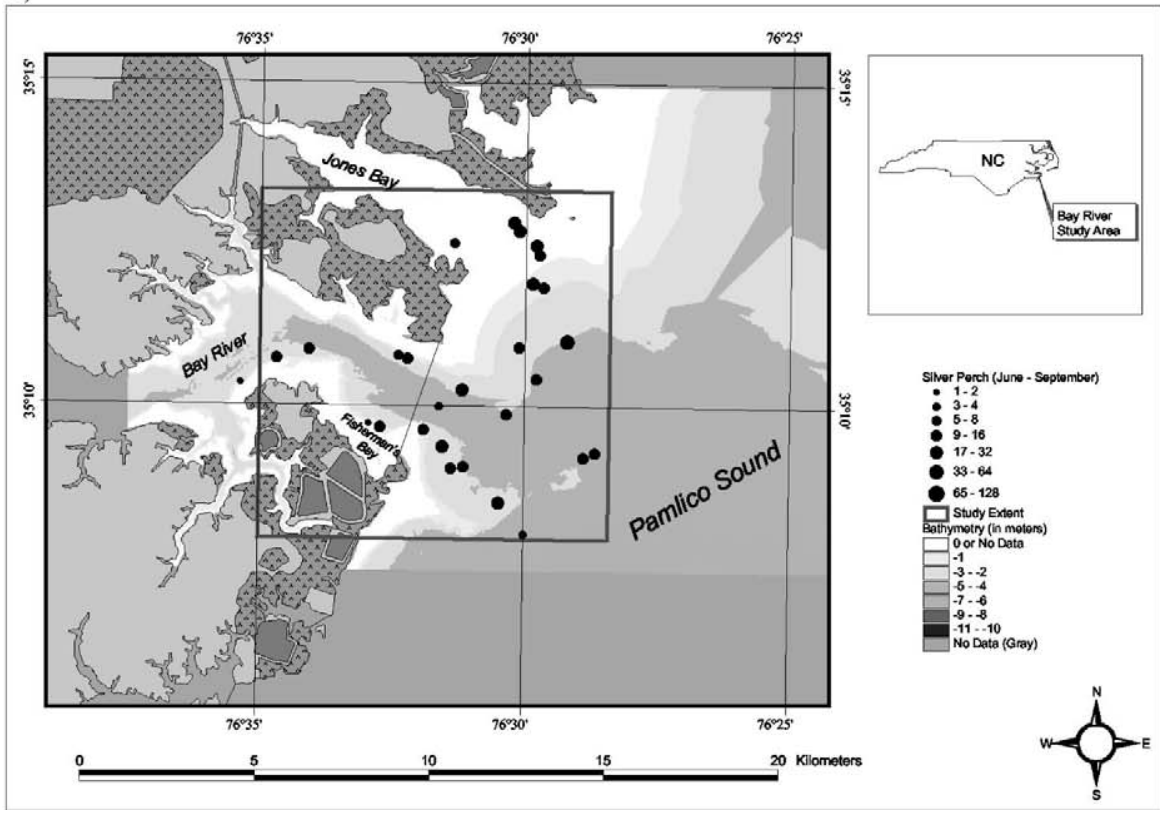

FIGURE 11.- Silver perch summed nightly drumming index (SNDI; larger circle size indicates a greater SNDI) derived from sonobuoys deployed in two areas of Pamlico Sound, North Carolina, during 1998: (A) Ocracoke Inlet (May-September) and (B) Bay River (June-September). Only sonobuoy locations that were positive for the species' presence are shown.

perch) or ceasing a few hours later (spotted seatrout). Spawning and sound production began in May for weakfish and silver perch and lasted until August; these two species appeared to have the longest spawning season as evidenced by sound production. Sound production by spotted seatrout started in June, peaked in July, and lasted until August. Sound production by red drum was restricted to August and September.

Variations in sound production were also related to variation in habitat variables, including water temper- 
A)

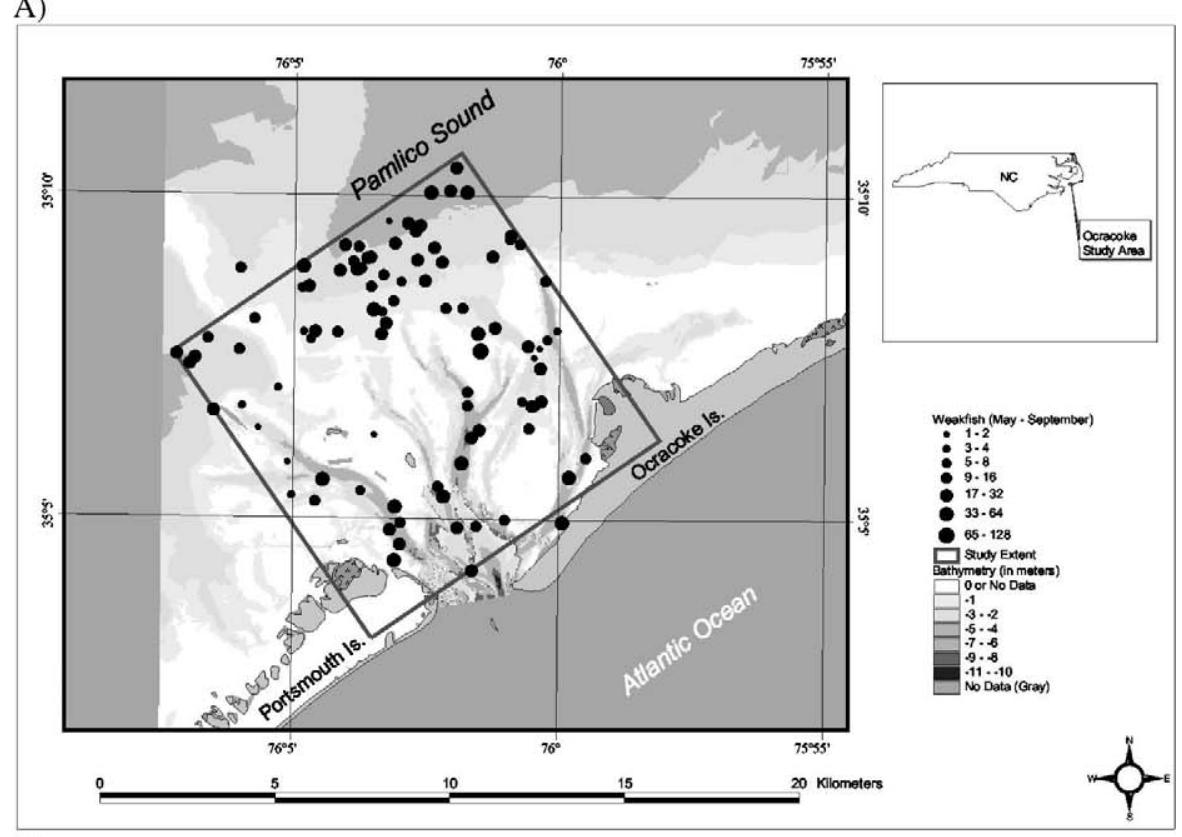

B)

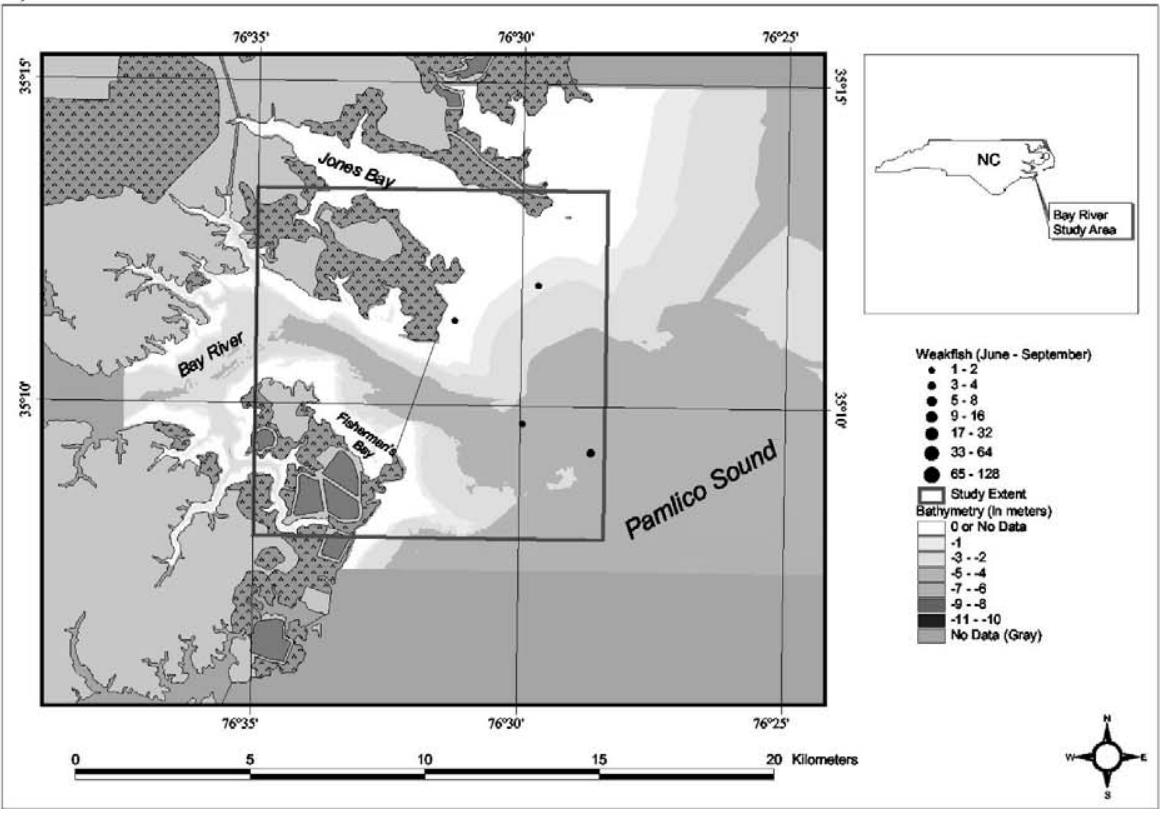

FIGURE 12.-Weakfish summed nightly drumming index (SNDI; larger circle size indicates a greater SNDI) derived from sonobuoys deployed in two areas of Pamlico Sound, North Carolina, during 1998: (A) Ocracoke Inlet (May-September) and (B) Bay River (June-September). Only sonobuoy locations that were positive for the species' presence are shown.

ature, salinity, dissolved oxygen concentration, depth, and proximity to the Bay River mouth or Ocracoke Inlet. The water quality conditions associated with sound production were typical for summertime in Pamlico Sound: hypoxia sometimes occurred near the river mouths, temperature ranged from $20^{\circ} \mathrm{C}$ to $30^{\circ} \mathrm{C}$, and salinity ranged from $8 \%$ to $25 \%$. However, there were significant differences among the species in the use of Pamlico Sound habitats for sound production and spawning. For example, weakfish and red drum 
A)

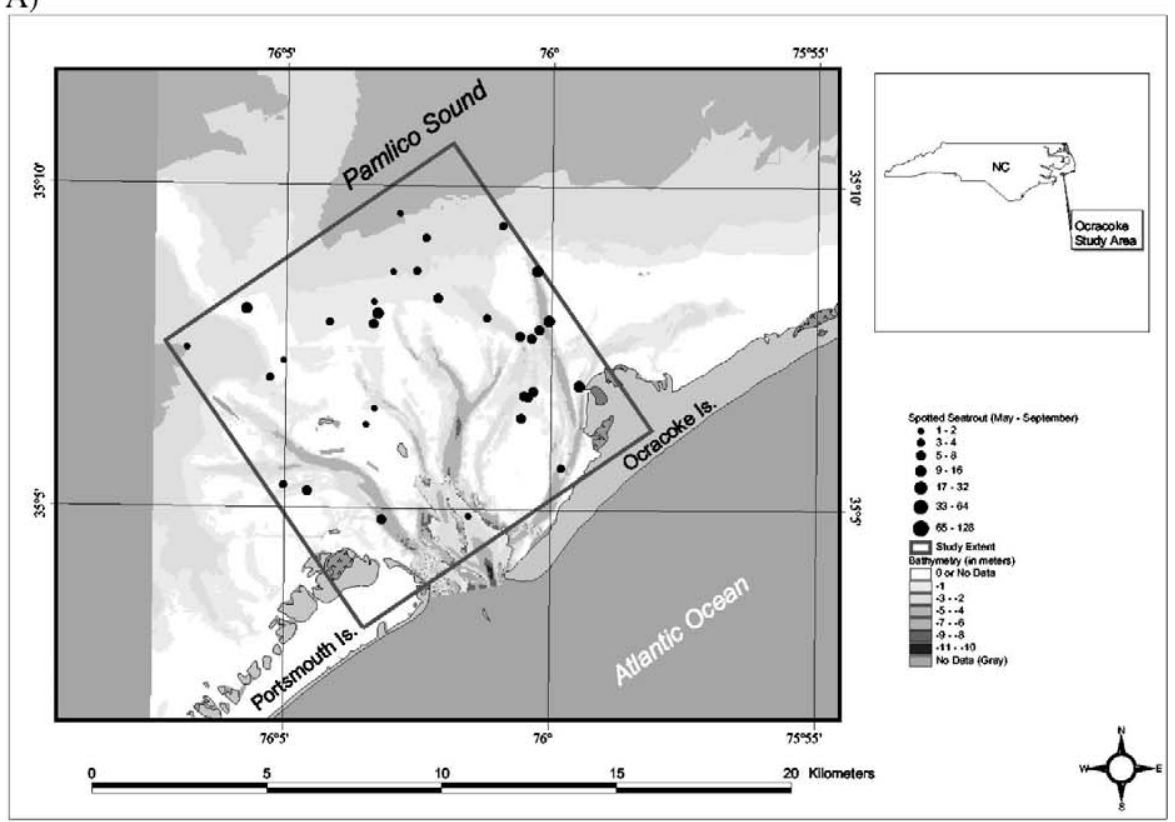

B)

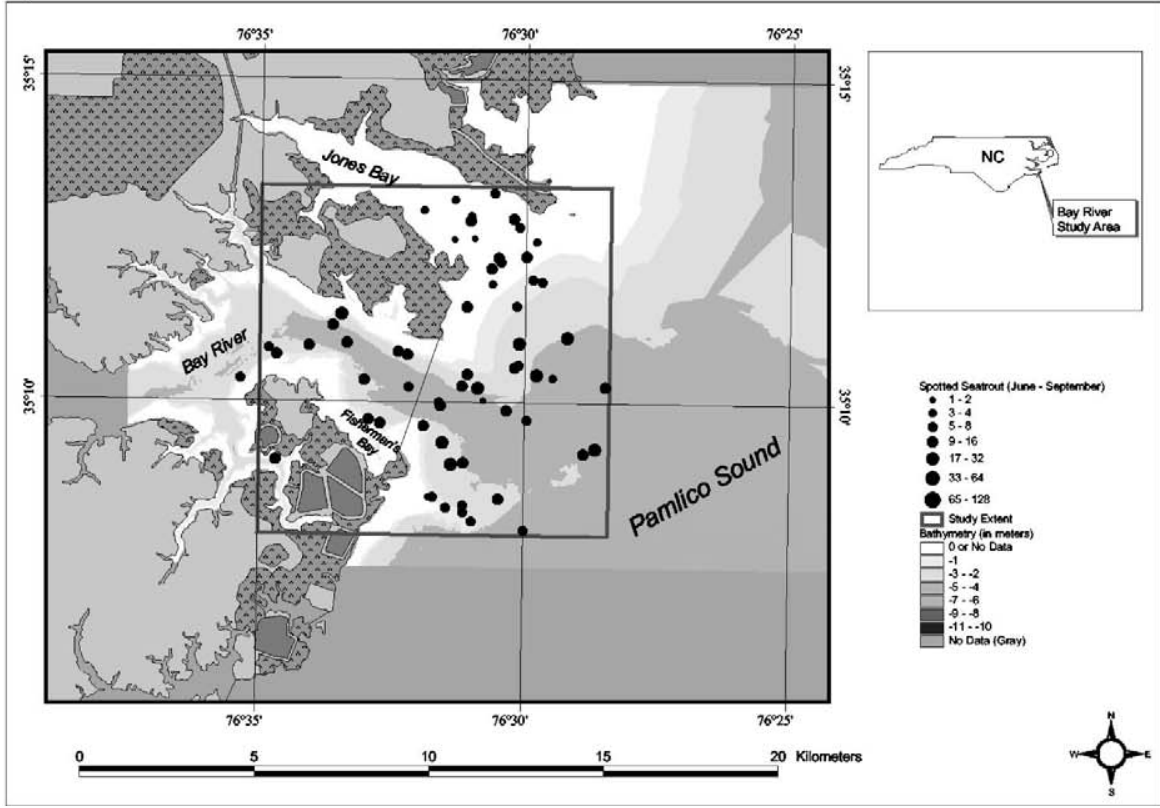

FIGURE 13.- Spotted seatrout summed nightly drumming index (SNDI; larger circle size indicates a greater SNDI) derived from sonobuoys deployed in two areas of Pamlico Sound, North Carolina, during 1998: (A) Ocracoke Inlet (May-September) and (B) Bay River (June-September). Only sonobuoy locations that were positive for the species' presence are shown.

preferred deep water $(>3 \mathrm{~m})$ for sound production, but silver perch and spotted seatrout produced sounds in shallow $(<3 \mathrm{~m})$ and deep strata equally. The CART analysis demonstrated the most critical habitat variables associated with sound production (high SNDI values) for each species. Silver perch were recorded primarily in cool waters with bottom dissolved oxygen concentrations lower than $7.4 \mathrm{mg} / \mathrm{L}$ and temperatures less than $26^{\circ} \mathrm{C}$. Weakfish used the deep waters $(>5 \mathrm{~m})$ of Ocracoke Inlet. Spotted seatrout inhabited Bay River 
A)

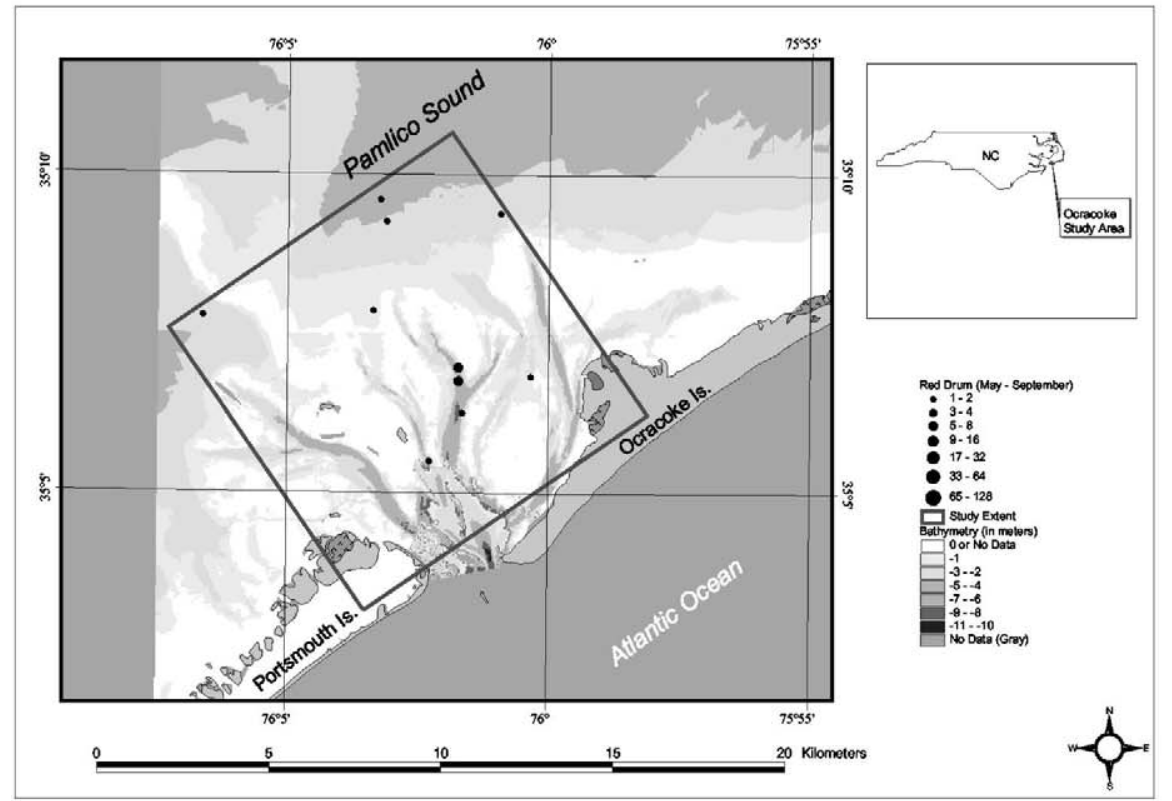

B)

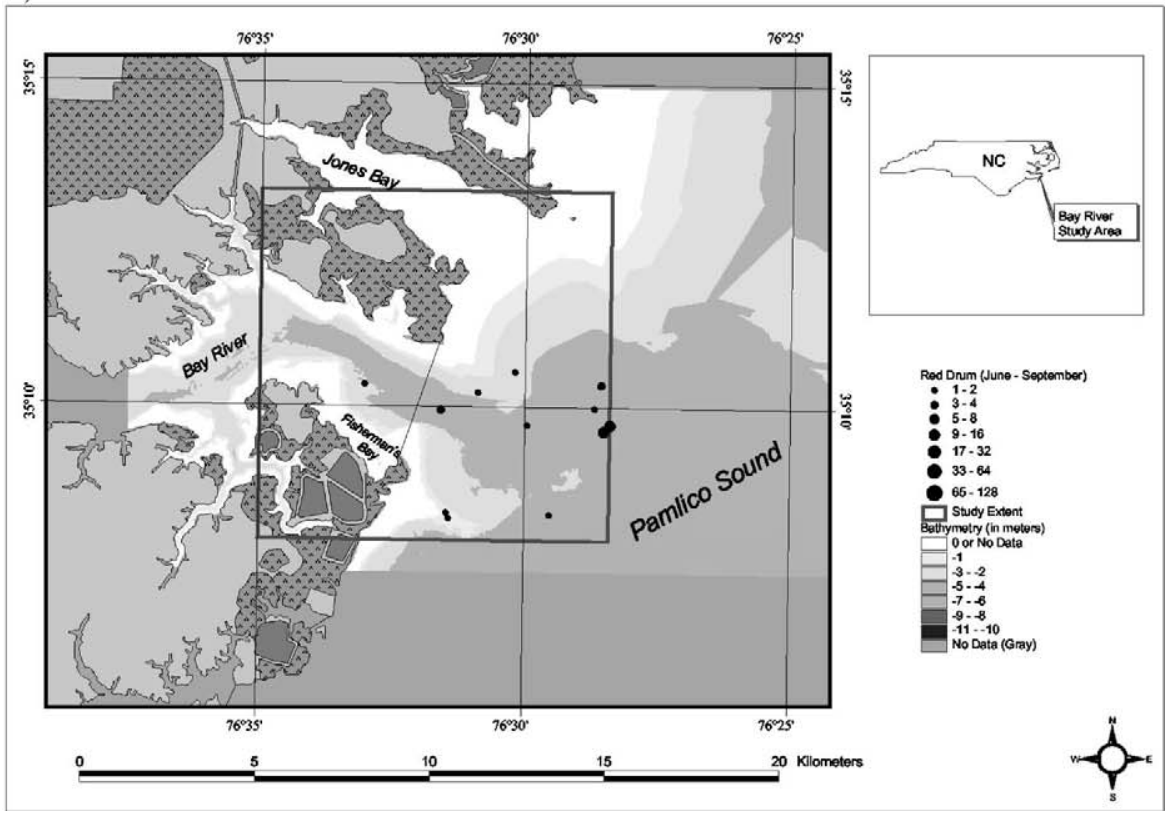

FIGURE 14.--Red drum summed nightly drumming index (SNDI; larger circle size indicates a greater SNDI) derived from sonobuoys deployed in two areas of Pamlico Sound, North Carolina, during 1998: (A) Ocracoke Inlet (May-September) and (B) Bay River (June-September). Only sonobuoy locations that were positive for the species' presence are shown.

sites where surface temperature exceeded $28^{\circ} \mathrm{C}$. Red drum calling activity occurred primarily where surface salinity exceeded $22 \%$. Dissolved oxygen and salinity were not limiting factors for all species; indeed, spotted seatrout produced sounds in low-salinity $(<12 \%)$ and hypoxic waters (dissolved oxygen $<5 \mathrm{mg} / \mathrm{L}$ ). However, low salinity and hypoxia did appear to limit sound production of weakfish, which produced few sounds when salinity was below $11 \%$ or when dissolved oxygen was below $5 \mathrm{mg} / \mathrm{L}$. Hypoxic bottom 

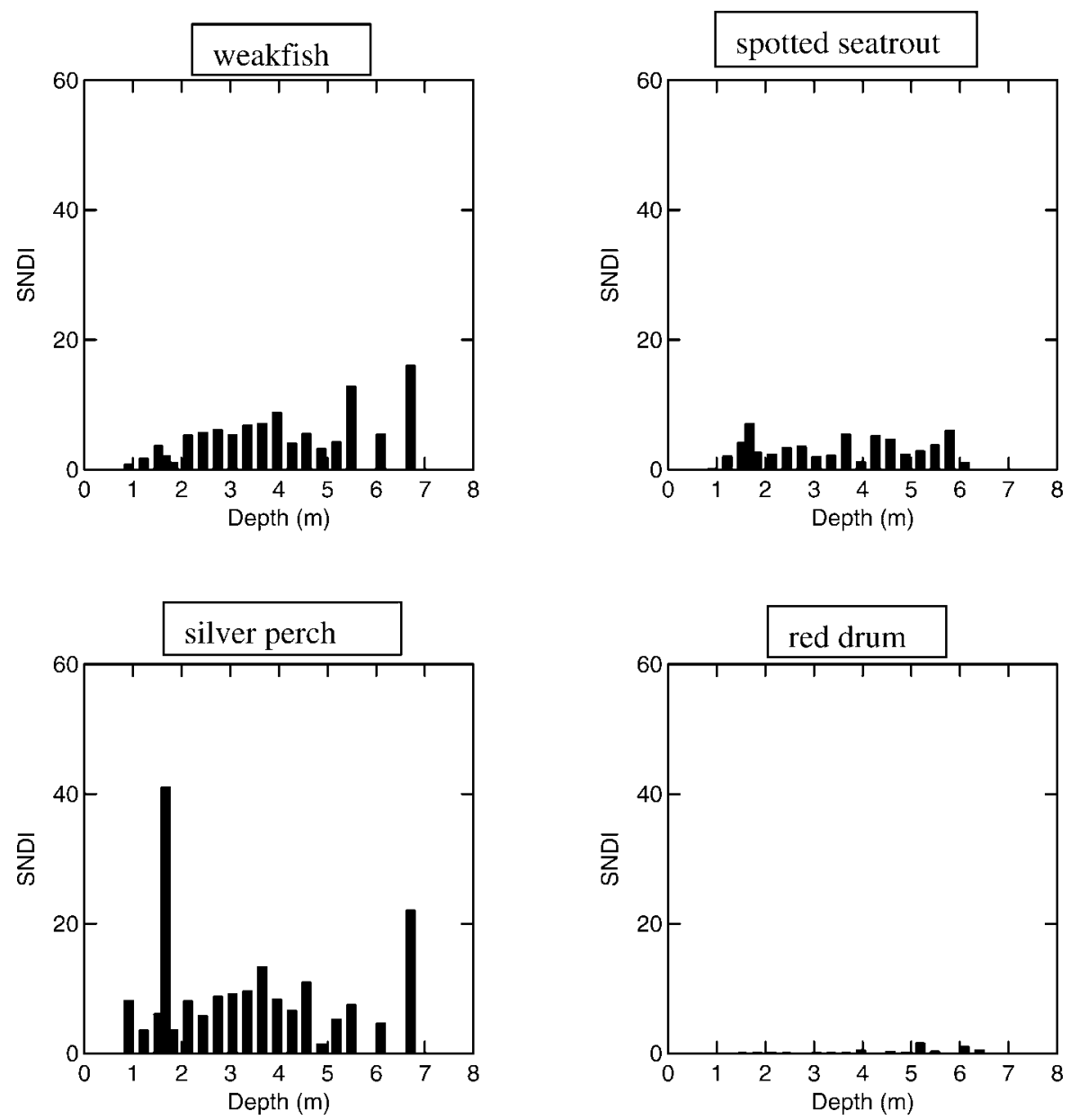

FIGURE 15.-Bar graphs of the summed nightly drumming index (SNDI) of weakfish, spotted seatrout, silver perch, and red drum recorded at various sonobuoy locations and depths ( 1-7 m) in Pamlico Sound, North Carolina, 1998.

waters occurred frequently in the Bay River area in summer and were more common in this area than at Ocracoke Inlet.

Differences in water quality and habitat between Bay River and Ocracoke Inlet were associated with the distribution of sound production sites used for spawning by weakfish and spotted seatrout. Weakfish do not commonly produce sound in low-salinity areas of Pamlico Sound and thus avoid spawning in hypoxic regions near the river mouths in the summer, whereas spotted seatrout do not appear to be limited by low salinity or low dissolved oxygen at river mouths. This distribution for spotted seatrout in Pamlico Sound contrasts with the salinity distribution of their spawning locations in other estuaries, as reviewed by Holt and Holt (2003). Those authors characterized spotted seatrout as mesohaline or polyhaline spawners that avoid spawning in salinities lower than approximately $18 \%$. Our findings suggest an oligohaline distribution for spawning spotted seatrout in Pamlico Sound, which could be due to the local population's preference for lower-salinity habitats. This could be an actual preference for low-salinity habitats or could be due to other factors, such as (1) avoidance of acoustic competition with weakfish (as in toads: Bosch and Marquez 1996; birds: Naugler and Ratcliffe 1994; and oyster toadfish: Fine and Thorson 2008); (2) competition for other resources; or (3) proximity to nursery habitats. We do not know the reproductive success of the male spotted seatrout calling in these low-salinity, hypoxic habitats, but we suspect that it is low because of the poor survivorship of eggs in such low-salinity water (Holt and Holt 2003). Possibly, these fish have been displaced to lower-quality spawning sites by 

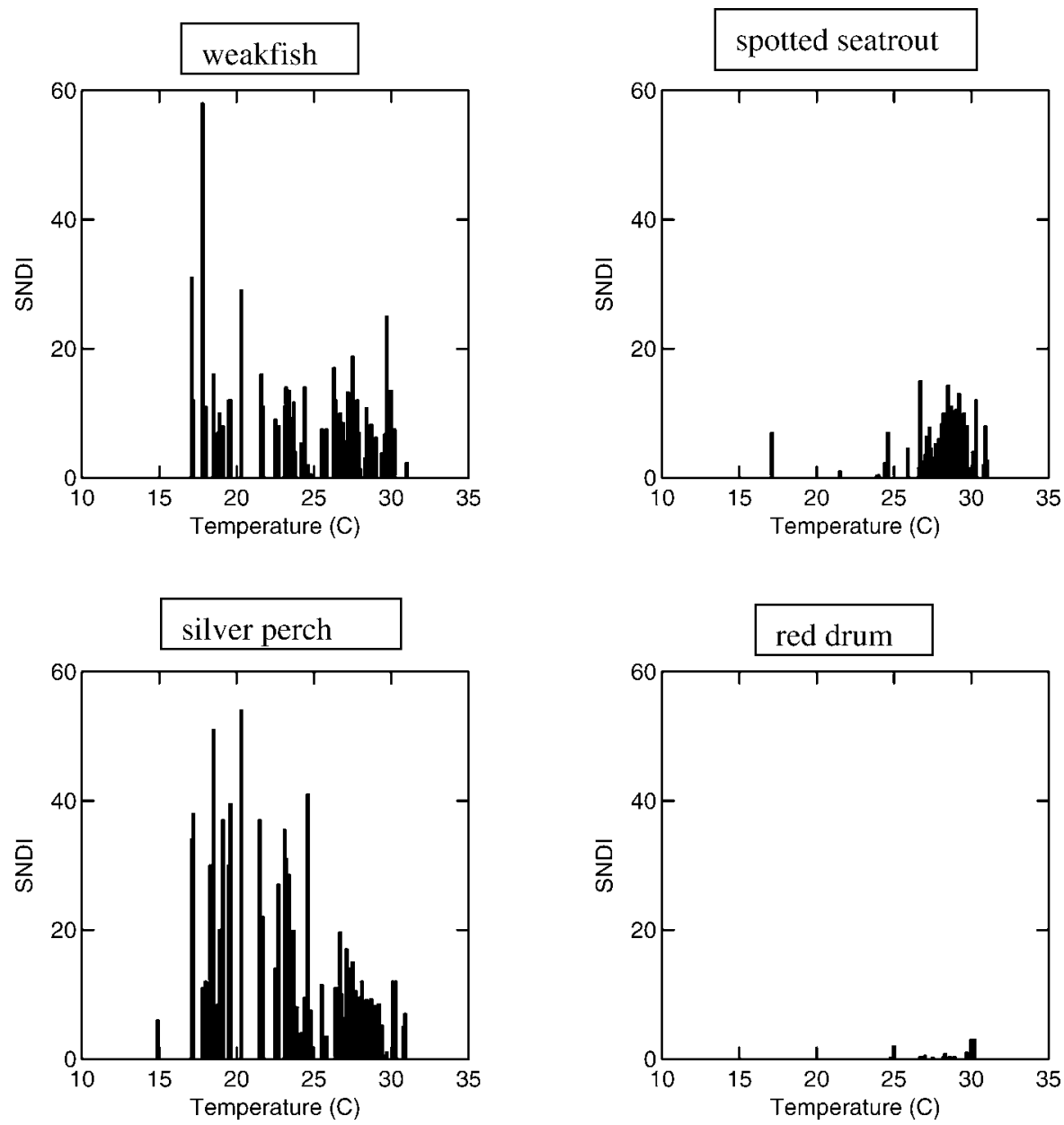

FIGURE 16.-Bar graphs of the summed nightly drumming index (SNDI) of weakfish, spotted seatrout, silver perch, and red drum recorded at various sonobuoy locations and bottom temperatures $\left(\sim 17-31^{\circ} \mathrm{C}\right)$ in Pamlico Sound, North Carolina, 1998.

TABLE 2.-Physical characteristics of essential fish habitat for silver perch, weakfish, spotted seatrout, and red drum in Pamlico Sound, North Carolina, measured at their respective sound production locations. Average (SD) bottom depth, temperature, salinity, and dissolved oxygen were measured at sonobuoy locations at the time of deployment.

\begin{tabular}{ccccc}
\hline $\begin{array}{c}\text { Species and } \\
\text { depth stratum }\end{array}$ & $\begin{array}{c}\text { Bottom } \\
\text { depth }(\mathrm{m})\end{array}$ & Temperature $\left({ }^{\circ} \mathrm{C}\right)$ & Salinity (\%) & $\begin{array}{c}\text { Dissolved } \\
\text { oxygen }(\mathrm{mg} / \mathrm{L})\end{array}$ \\
\hline $\begin{array}{l}\text { Silver perch } \\
\text { Surface }\end{array}$ & & & & \\
$\quad$ Bottom & $3.2(1.3)$ & $26.4(3.4)$ & $13.0(4.1)$ & $7.9(0.8)$ \\
$\begin{array}{c}\text { Weakfish } \\
\text { Surface }\end{array}$ & & $25.6(3.6)$ & $14.0(4.7)$ & $7.0(1.8)$ \\
$\quad$ Bottom & $3.2(1.3)$ & $26.0(2.9)$ & $14.4(4.1)$ & $7.9(0.9)$ \\
$\begin{array}{l}\text { Spotted seatrout } \\
\text { Surface }\end{array}$ & & $25.3(3.5)$ & $15.4(4.5)$ & $7.6(1.1)$ \\
$\quad$ Bottom & $2.9(1.3)$ & $28.8(1.8)$ & $11.2(3.2)$ & $7.7(0.7)$ \\
Red drum & & $28.0(1.9)$ & $11.8(3.5)$ & $6.1(1.3)$ \\
$\quad \begin{array}{l}\text { Surface } \\
\text { Bottom }\end{array}$ & $4.1(1.5)$ & $27.7(2.2)$ & $14.8(6.1)$ & $7.8(1.1)$ \\
\hline
\end{tabular}



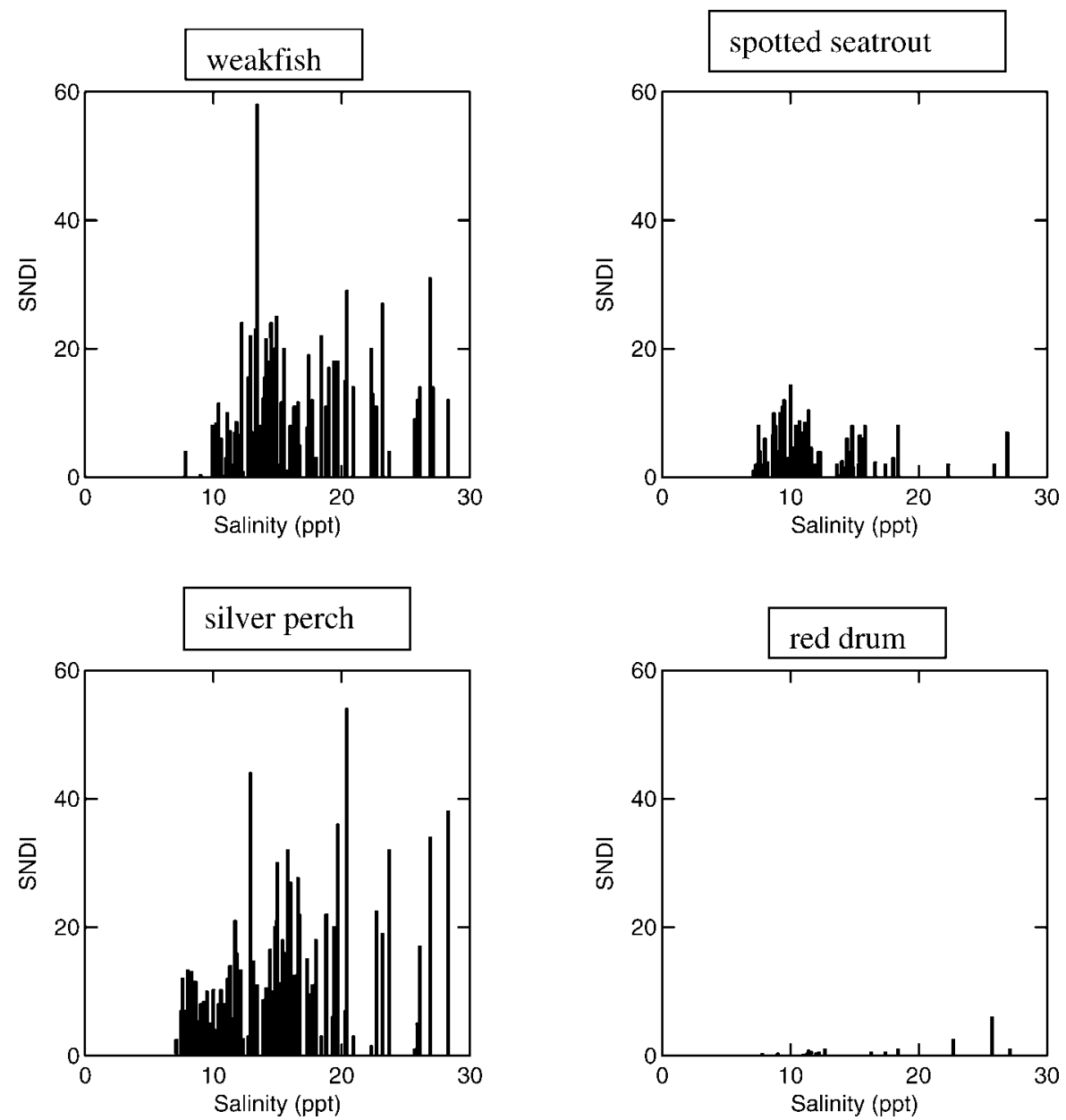

FIGURE 17.-Bar graphs of the summed nightly drumming index (SNDI) of weakfish, spotted seatrout, silver perch, and red drum recorded at various sonobuoy locations and bottom salinities ( 8-27\%) in Pamlico Sound, North Carolina, 1998.

competition with weakfish closer to the inlets. It is important to note that our water quality sampling was neither continuous nor conducted simultaneously with sound production (we performed daytime sampling for water quality, whereas most sound production was during evening hours), but because the measurements were made on the same day as the sound recordings, it is very unlikely to have changed dramatically. We do not know whether short-term fluctuations in bottom hypoxia affected sound production and spawning, and further work should be done with the Cynoscion congeners in this area of sympatry; we suggest using continuously recording acoustic and water quality instruments and concurrent ichthyoplankton surveys.

Our findings agree with those of other researchers that have used passive acoustic approaches to identify estuarine spawning areas of these same species in other locations. For example, Connaughton and Taylor (1995, 1996) described the nocturnal and seasonal changes in sound production of weakfish in Delaware Bay and demonstrated that such changes were associated with nocturnal spawning in the laboratory. Those authors found that drumming by male weakfish peaked in May and decreased in July. Lowerre-Barbieri et al. (1996) demonstrated that female weakfish in Chesapeake Bay had a spawning peak in May, as determined by examining oocytes, estimating gonadal stage, and measuring the gonadosomatic index; their findings agree with the timing of peak spawning based on our passive acoustic surveys of males in Pamlico Sound. In a previous study at Ocracoke Inlet, we delimited spawning areas of weakfish and correlated nocturnal egg abundance with sound pressure levels, and peak levels of both sound production and egg 

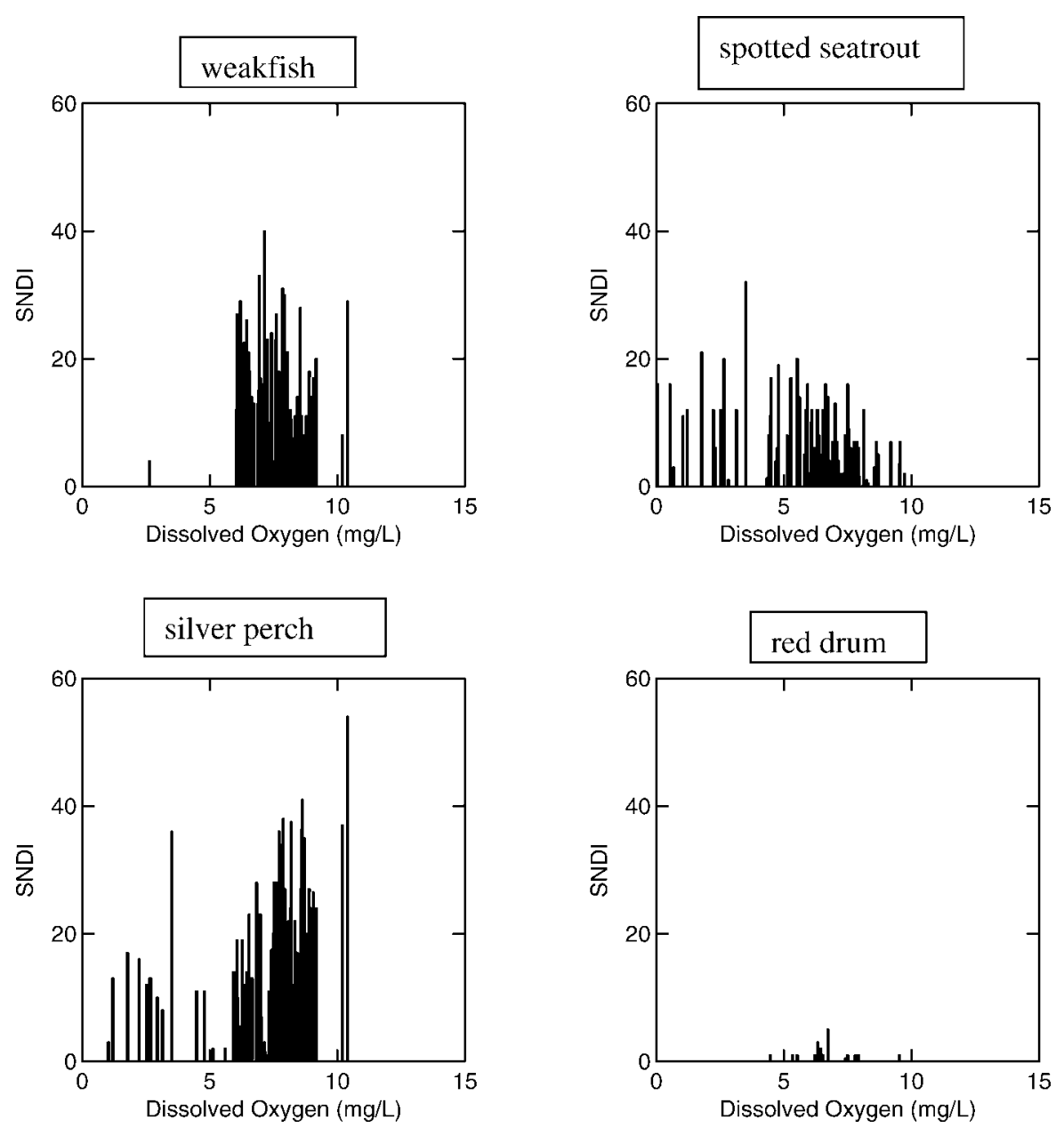

FIGURE 18.-Bar graphs of the summed nightly drumming index (SNDI) of weakfish, spotted seatrout, silver perch, and red drum recorded at various sonobuoy locations and bottom dissolved oxygen levels $(\sim 2-11 \mathrm{mg} / \mathrm{L})$ in Pamlico Sound, North Carolina, 1998.

production occurred in May (Luczkovich et al. 1999). In Florida's Indian River Lagoon, spotted seatrout and silver perch spawning areas were identified via hydrophone surveys of nocturnal sound production, which was associated with spawning and egg production; calling activity occurred during January-June (peak in March) for silver perch, whereas spotted seatrout sound production began in March and ended in May, when sampling ceased (Mok and Gilmore 1983). Thus, the dates of spawning and sound production for these species may be occurring earlier in the year in Florida than in North Carolina. Similarly, Saucier and Baltz (1993), Saucier et al. (1992), and Roumillat and Brouwer (2004) located sound-producing spotted seatrout during nighttime hydrophone surveys and related these sounds to egg production in Louisiana and
South Carolina estuaries. Saucier et al. (1992) only sampled in August in Charleston Estuary, South Carolina, and thus no seasonal comparison can be made; however, Saucier and Baltz (1993) recorded spotted seatrout during May-October in Louisiana. Guest and Lasswell (1978) demonstrated in laboratory studies that nocturnal sound production by spawning red drum was associated with males courting females. Holt et al. (1985) determined that red drum and other sciaenids are nocturnal spawners, based on egg collections off the coast of Texas. Using a passive acoustic towed hydrophone array, Holt (2008, this issue) located red drum sound production sites in Texas coastal regions (but not in estuaries). Red drum spawning was identified via planktonic egg collection and hydrophone surveys during October and Novem- 


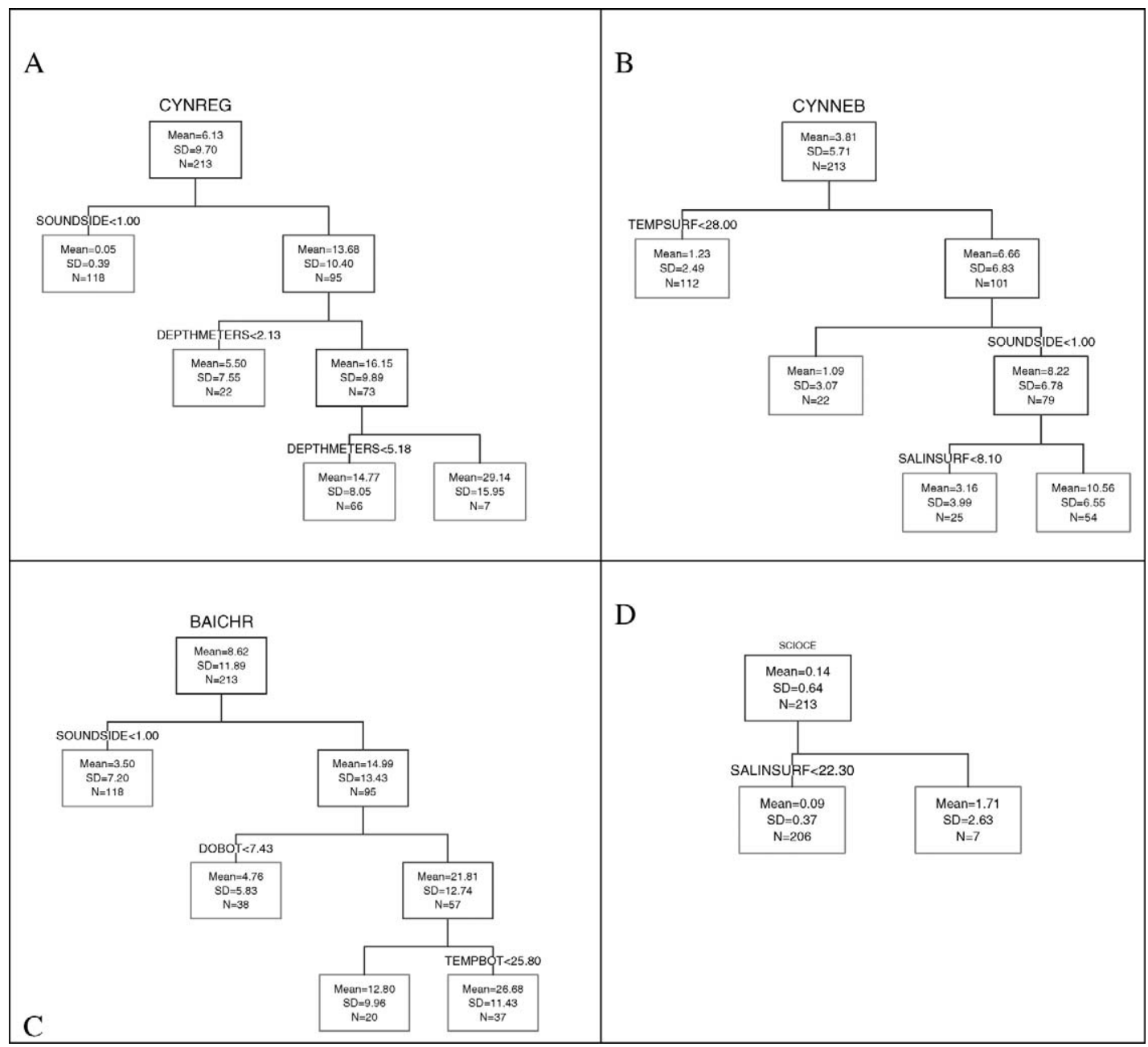

FIGURE 19.- - Results of a classification and regression tree analysis of habitat variables (sound side; bottom depth [DEPTHMETERS], $\mathrm{m}$; surface temperature [TEMPSURF], ${ }^{\circ} \mathrm{C}$; bottom temperature [TEMPBOT]; surface salinity [SALINSURF], \%; bottom salinity; surface dissolved oxygen, $\mathrm{mg} / \mathrm{L}$; and bottom dissolved oxygen [DOBOT]) used to predict the summed nightly drumming index for (A) weakfish (CYNREG), (B) spotted seatrout (CYNNEB), (C) silver perch (BAICHR), and (D) red drum (SCIOCE) in Pamlico Sound, North Carolina.

ber in the Mosquito River estuary, Florida; the greatest egg production occurred in areas of high salinity $(>25 \%)$ and was sometimes associated with sound production . Because they used mobile hydrophone techniques rather than automatic sonobuoys, Johnson and Funicelli (1991) may have missed periods of drumming activity that preceded egg production and spawning.

Our study showed that sound production by male red drum occurred in low-salinity areas (Bay River mouth: $\sim 12 \%$ ) and high-salinity areas (Ocracoke Inlet: $\sim 17 \%$ ) in September, but the greatest SNDI was associated with high salinities. Using synoptic methods to describe the temporal and spatial distribution of the spawning populations of these four sciaenids, our study is the first to examine an entire season in a single estuary where all four species occur.

This passive acoustic survey allowed us to discover temporal and spatial patterns of sound production and, by inference, those of egg production and spawning activity (Luczkovich et al. 1999). Because no fish were killed, this was a noninvasive method of determining $\mathrm{EFH}$ use, at least at EFH level 1 (presence or absence). We suggest here that the SNDI can be used as a measure of relative abundance as well, giving an index of the abundance of the spawning stock as it varies 
spatially and temporally (i.e., EFH level 2 or higher). This assertion depends on the equal likelihood of sonobuoy detection for all species of sciaenids during the night, which is likely because we sampled throughout the night with all sonobuoys. However, the SNDI weights species that call longer in the evening (silver perch and weakfish) more than those that call only after sunset (spotted seatrout and red drum). We need more observations on individual fishes in situ (Sprague and Luczkovich 2004) or in laboratory studies to determine whether individual fish in the population call for a longer duration in these species or whether individuals call for only part of the night, which would mean that more calling fish are present in the area (i.e., greater population size). We need to validate this assertion by comparing the SNDI with an unbiased estimate of adult abundance, which can be obtained using active acoustic echosounders and with absolute sound pressure levels measured in specific frequency ranges associated with the various species.

If we assume that it is a measure of relative abundance, the SNDI indicates that (1) male silver perch, spotted seatrout, and weakfish were relatively abundant during the months surveyed in 1998; (2) these populations were spawning regularly in Pamlico Sound; and (3) red drum were rare or absent. This is in agreement with the stock assessments based on fishery catch data for these species. Red drum are stressed or declining, as noted earlier (Vaughan and Carmichael 2002), and are under harvest restrictions. There is some controversy regarding the estuarine spawning of red drum (see Johnson and Funicelli 1991; Holt 2008), but we conclude that populations of male red drum make spawning sounds and are likely to spawn in Pamlico Sound, even at low salinities (12-13\%o). Further passive acoustic, ichthyoplankton, and adult surveys in the Atlantic Ocean are required to assess the possibility of offshore sound production and spawning by red drum.

Passive acoustic surveys have been done in the past using small boats with the engine shut off and a hydrophone and recorder deployed over the side. These mobile passive acoustic surveys are useful for preliminary studies and to support biological sampling, such as ichthyoplankton surveys (Mok and Gilmore 1983; Johnson and Funicelli 1991; Luczkovich et al. 1999), but they lack the synoptic sampling efforts that can be achieved with automated passive acoustic samplers. The sonobuoy we used was an inexpensive analog system similar to the automated audio recorders being used to record calls and vocalizations in other taxa (e.g., amphibians: Bridges and Dorcas 2000). In our analog system, a human analyst must still listen to the cassette tapes and record the data as a qualitative index. A new generation of digital automated recording devices is being developed that can handle the processing and discrimination of species remotely and can reduce the related data set (i.e., presence or absence of fish of each species or an index of drumming intensity). By implementing a digital recording device, we can provide rapid and widespread monitoring of sound-producing fishes.

The deployment of sonobuoys and other autonomous recording devices has several advantages over passive acoustic sampling from a boat. First, multiple sonobuoys can be made to start recording at the same time in the evening, allowing temporal comparison of spawning sound activity between locations. When one records from a boat, one is limited to the area that can be covered in a single evening and the recordings are not made simultaneously. Finally, access to these nocturnal spawners is limited by the difficulty of navigating a small boat in the dark, which is dangerous. The sonobuoys were designed to record for an entire night on one 45- or 50-min cassette tape. This was accomplished by sampling for a relatively short period (90 s) at intervals of 30 or $60 \mathrm{~min}$. Our recordings from previous work (Luczkovich et al. 1999) suggested that a short recording can adequately characterize the number of species sounds present at a given time for a given location. Mok and Gilmore (1983) used a short (2-min) recording length for their automated recordings of fish sound production in Florida.

Discrimination among the four sciaenids can be accomplished using bioacoustic and spectral analyses (oscillograms and spectrograms) that are easily implemented on a computer. Our species-specific spectral analyses are in agreement with the sound identifications based on captive or in situ recordings of these fishes by other investigators. The species-specific nature of these calls have been previously described via spectrograms in other studies: Fish and Mowbray (1970) described the calls and provided spectrograms of silver perch, weakfish, and red drum recorded in captivity; Guest and Lasswell (1978) showed a spectrogram of red drum recorded in captivity; Mok and Gilmore (1983) characterized the calls of silver perch and spotted seatrout in situ; Connaughton and Taylor (1996) and Connaughton et al. (1997, 2000) described the pattern and mechanism of sound production by weakfish in captivity; Perkins (2001) described the drumming sound of weakfish in situ and distinguished it from the chattering sounds initially described by Fish and Mowbray (1970) as being produced by weakfish but subsequently confirmed by Mann et al. (1997) and Sprague and Luczkovich (2001) as being produced by striped cusk-eels Ophidion marginatum; Gilmore (2003) described the spectral 
characteristics of spotted seatrout calls in situ; and Sprague et al. (2000) described the spectrograms, oscillograms, and average power spectra of the sciaenids studied here (Sprague et al. [2000] used the same captive recordings used in this paper, but different in situ recordings).

These spectral analysis methods can be transferred into computer algorithms that can be fully automated and implemented on remote sensors in coastal observatories. The passive acoustic approach is simple and cost effective (each sonobuoy costs $<\$ 300$ ), requiring a minimal amount of computer resources. As noted above, passive acoustic digital recording systems are being developed with similar costs. We advocate that this passive acoustic monitoring approach be widely implemented in autonomous coastal observatories and linked in real time to fisheries managers, such as the planned ocean and coastal observing systems (Malone 2003). In this way, spawning activity of soniferous fishes can be monitored, and independently derived spawning stock biomass assessments can be compared with these indexes. If the relationship between spawning activity (as measured with passive acoustics) and traditional spawning stock size is validated, spawning fish assessments can integrated into ocean observing platforms.

Finally, based on our passive acoustic data, estuarine spawning habitat maps have been generated for the four sciaenids. Specific spawning areas, spawning times, and characteristic habitat conditions (temperature, salinity, dissolved oxygen, and depth) were identified. We have provided this information to the NCDMF, and the maps have been incorporated into management plans for red drum (Daniels 2001). In the future, these spawning maps can be used to establish "no-take" (harvest closure) areas for spawning sanctuaries, which have been effective at producing large individual fish sizes and increased stock sizes of red drum and spotted seatrout in Florida (Johnson et al. 1999). Although these spawning sanctuaries are not currently in place in North Carolina, they can be implemented by proclamation of the NCDMF director whenever these populations show stress from commercial or recreational fishing.

In summary, we have developed and successfully deployed a series of automated sound recorders that were able to provide patterns of EFH use and relative abundance of four ecologically, commercially, and recreationally important sciaenids during their spawning periods. We can envision a time when such methods of fish monitoring will become routine and part of coastal observatories, and we hope that other fishery biologists and managers will consider these passive acoustic approaches as cost-effective methods of assessing stocks of soniferous fishes.

\section{Acknowledgments}

This work was funded by the NCDMF, Federal Aid in Sport Fish Restoration Program (Dingell-Johnson Act) through the Wallop-Breaux Amendment, and U.S. Fish and Wildlife Service Grant Number F-62. In addition, we were supported during this work with boat, equipment, and supplies from the East Carolina University Departments of Biology, Physics, and Geology and Institute for Coastal Marine Resources. We are grateful to the U.S. Coast Guard Group Hatteras, Station Ocracoke, and Group Fort Macon, Station Hobucken, for the use of their docking facilities and to North Carolina State University's Pamlico Aquaculture Field Laboratory for use of the holding tanks. Special acknowledgment goes to Hal J. Daniel III and Todd Jenkins, who helped deploy and maintain the sonobuoys, and Marcy Hutchinson-Chen, who listened to a great many sonobuoy tapes and whose work was essential in the completion of this data analysis.

\section{References}

Akamatsu, T., T. Okumura, N. Novarini, and H. Y. Yan. 2002. Empirical refinements applicable to the recording of fish sounds in small tanks. Journal of the Acoustical Society of America 112:3073-3082.

Allison, G. W., J. Lubchenco, and M. H. Carr. 1998. Marine reserves are necessary but not sufficient for marine conservation. Ecological Applications 8(supplement):7982.

Barros, N. B., and D. K. Odell. 1990. Food habits of the bottlenose dolphin in the southeastern United States. Pages 309-328 in S. Leatherwood and R. Reeves, editors. The bottlenose dolphin. Academic Press, New York.

Benaka, L., editor. 1999. Fish habitat: essential fish habitat and rehabilitation. American Fisheries Society, Symposium 22, Bethesda, Maryland.

Bosch, J., and R. Marquez. 1996. Acoustic competition in male midwife toads Alytes obstetricans and Alytes cisternasii: response to neighbor size and calling rate. Ethology 102:841-855.

Bridges, A. S., and M. E. Dorcas. 2000. Temporal variation in anuran calling behavior: implications for surveys and monitoring programs. Copeia 2000:587-592.

Brown-Peterson, N., P. Thomas, and C. R. Arnold. 1988. Reproductive biology of the spotted seatrout, Cynoscion nebulosus, in south Texas. U.S. National Marine Fisheries Service Fishery Bulletin 86:373-388.

Burkenroad, M. D. 1931. Notes on the sound-producing marine fishes of Louisiana. Copeia 1931:20-29.

Clark, C. W. 1996. Marine reserves and the precautionary management of fisheries. Ecological Applications 6:369.

Connaughton, M. A., M. L. Fine, and M. H. Taylor. 1997. The effects of seasonal hypertrophy and atrophy on fiber morphology, metabolic substrate concentration and 
sound characteristics of the weakfish sonic muscle. Journal of Experimental Biology 200:2449-2457.

Connaughton, M. A., and M. H. Taylor. 1995. Seasonal and daily cycles in sound production associated with spawning in weakfish, Cynoscion regalis. Environmental Biology of Fishes 42:233-240.

Connaughton, M. A., and M. H. Taylor. 1996. Drumming, courtship, and spawning behavior in captive weakfish, Cynoscion regalis. Copeia 1996:195-199.

Connaughton, M. A., M. H. Taylor, and M. L. Fine. 2000. Effects of fish size and temperature on weakfish disturbance calls: implications for the mechanism of sound generation. Journal of Experimental Biology 203:1503-1512.

Daniel, L. B., and J. E. Graves. 1994. Morphometric and genetic identification of eggs of spring-spawning sciaenids in lower Chesapeake Bay. U.S. National Marine Fisheries Service Fishery Bulletin 92:254-261.

Daniels, L. B. 2001. Red drum fishery management plan. North Carolina Department of Environment and Natural Resources, Division of Marine Fisheries, Morehead City. Available: ncfisheries.net. (February 2008).

De'ath, G., and K. E. Fabricus. 2000. Classification and regression trees: a powerful yet simple technique for ecological data analysis. Ecology 81:3178-3192.

Fine, M.A., and R. F. Thorson. 2008. Use of passive acoustics for assessing behavioral interactions in individual toadfish in the field. Transactions of the American Fisheries Society 137:627-637.

Fish, M. P., and W. H. Mowbray. 1970. Sounds of the Western North Atlantic Fishes. Johns Hopkins Press, Baltimore, Maryland.

Gilmore, R. G. 2003. Sound production and communication in the spotted seatrout. Pages 177-195 in S. A. Bortone, editor. Biology of the Spotted Seatrout. CRC Press, Boca Raton, Florida.

Guenette, S., T. Lauck, and C. Clark. 1998. Marine reserves: from Beverton and Holt to the present. Reviews in Fish Biology and Fisheries 8:251-272.

Guest, W. C., and J. L. Lasswell. 1978. A note on courtship behavior and sound production of red drum. Copeia 1978:337-338.

Hawkins, A. D., and K. J. Rasmussen. 1978. The calls of gadoid fish. Journal of the Marine Biology Association UK 58:881-911.

Heyer, W. R., M. A. Donnelly, R. W. McDiarmid, L. C. Hayek, and M. S. Foster, editors. 1994. Measuring and monitoring biological diversity: standard methods for amphibians. Smithsonian Institution Press, Washington, D.C.

Holt, J. G., and S. A. Holt. 2003. Effects of variable salinity on reproduction and early life stages of spotted seatrout. Pages 135-145 in S. A. Bortone, editor. Biology of the spotted seatrout. CRC Press, Boca Raton, Florida.

Holt, J. G., S. A. Holt, and C. R. Arnold. 1985. Diel periodicity of spawning in sciaenids. Marine Ecology Progress Series 27:1-7.

Holt, S. 2008. Distribution of red drum spawning sites identified by towed hydrophone array. Transactions of the American Fisheries Society 137:551-561.

Horne, J. K. 2000. Acoustic approaches to remote species identification: a review. Fisheries Oceanography 9:356371.

Kaatz, I. M. 2002. Multiple sound-producing mechanisms in teleost fishes and hypotheses regarding their behavioural significance. Bioacoustics 12:230-233.

Johnson, D. R., and N. A. Funicelli. 1991. Spawning of the red drum in Mosquito Lagoon, east-central Florida. Estuaries 14:74-79.

Johnson, D. R., N. A. Funicelli, and J. A. Bohnsack. 1999. Effectiveness of an existing estuarine no-take fish sanctuary within the Kennedy Space Center, Florida. North American Journal of Fisheries Management 19:436-453.

Lauck, T., C. W. Clark, and G. R. Munroe. 1998. Implementing the precautionary principle in fisheries management through marine reserves. Ecological Applications 8(supplement):72-77.

Lowerre-Barbieri, S., L. Barbieri, J. R. Flanders, A. Woodward, C. Cotton, and K. Knowlton. 2008. Using passive acoustics to determine red drum spawning in Georgia Waters. Transactions of the American Fisheries Society 137:562-575.

Lowerre-Barbieri, S. K., M. E. Chittenden, Jr., and L. R. Barbieri. 1996. The multiple spawning pattern of weakfish in the Chesapeake Bay and Middle Atlantic Bight. Journal of Fish Biology 48:1139-1163.

Luczkovich, J. J. 2007. Fish sounds. Department of Biology, East Carolina University, Greenville, North Carolina. Available: www.personal.ecu.edu/luczkovichj/ fishsounds/AFS_fish_sounds.htm.

Luczkovich, J. J., H. J. Daniel, III, M. Hutchinson, T. Jenkins, S. E. Johnson, R. C. Pullinger, and M. W. Sprague. 2000. Sounds of sex and death in the sea: bottlenose dolphin whistles suppress mating choruses of silver perch. Bioacoustics 10:323-334.

Luczkovich, J. J., M. W. Sprague, S. E. Johnson, and R. C. Pullinger. 1999. Delimiting spawning areas of weakfish Cynoscion regalis (Family Sciaenidae) in Pamlico Sound, North Carolina, using passive hydroacoustic surveys. Bioacoustics 10:143-160.

MacLennan, D. N., and E. J. Simmons. 1992. Fisheries acoustics. Chapman and Hall, London.

Malone, T. C. 2003. The coastal component of the U.S. Integrated Ocean Observing System. Environmental Monitoring and Assessment 81:51-62.

Mann, D. A., J. Bowers-Altman, and R. A. Rountree. 1997. Sounds produced by the striped cusk-eel Ophidion marginatum (Ophidiidae) during courtship and spawning. Copeia 1997:610-612.

Merriner, J. V. 1976. Aspects of the reproductive biology of the weakfish Cynoscion regalis (Sciaenidae) in North Carolina. Fisheries Bulletin 74:18-26.

Mok, H. K., and R. G. Gilmore. 1983. Analysis of sound production in estuarine fish aggregations of Pogonias cromis, Bairdiella chrysoura, and Cynoscion nebulosus (Sciaenidae). Bulletin of the Institute of Zoology, Academia Sinica 22:157-186.

Murphy, M. D., and R. G. Taylor. 1990. Reproduction, growth, and mortality of red drum Sciaenops ocellatus in Florida waters. U.S. National Marine Fisheries Service Fishery Bulletin 88:531-542.

Myrberg, A. A. 1981. Sound communication and interception 
in fishes. Pages 395-425 in W. N. Tavolga, A. N. Popper, and R. R. Fay, editors. Hearing and sound communication in fishes. Springer-Verlag, New York.

Naugler, C. T., and L. Ratcliffe. 1994. Character release in bird song: a test of the acoustic competition hypothesis using American tree sparrow Spizella arborea. Journal of Avian Biology 25:142-148.

Nordeide, J. T., and I. Folstad. 2000. Is cod lekking or a promiscuous group spawner? Fish and Fisheries 1:90-93.

North Carolina Division of Marine Fisheries. 2005. Commercial Statistics. Morehead City, North Carolina. Available: www.ncfisheries.net/statistics/index.html.(February 2008)

Ogden, J. C. 1997. Marine managers look upstream for connections. Science 278:1414-1415.

Parvulescu, A. 1967. The acoustics of small tanks. Pages 7-13 in W. N. Tavolga, editor. Marine bio-acoustics, volume 2. Pergamon Press, New York.

Perkins, P. J. 2001. Drumming and chattering sounds recorded underwater in Rhode Island. Northeastern Naturalist 8:359-370.

Peters, K. M., and R. H. McMichael, Jr. 1987. Early life history of the red drum, Sciaenops ocellatus (Pisces: Sciaenidae), in Tampa Bay, Florida. Estuaries 10:92107.

Roberts, C. M. 1997. Connectivity and management of Caribbean coral reefs. Science 278:1454.

Roumillat, W. A., and M. C. Brouwer. 2004. Reproductive dynamics of female spotted seatrout (Cynoscion nebulosus) in South Carolina. U.S. National Marine Fisheries Service Fishery Bulletin 102:473-487.

Saucier, M. H., and D. M. Baltz. 1992. Spawning site selection by spotted seatrout, Cynoscion nebulosus, and black drum, Pogonias cromis, in Louisiana. Environmental Biology of Fishes 36:257-272.

Saucier, M. H., D. M. Baltz, and W. A. Roumillat. 1992.
Hydrophone identification of spawning sites of spotted seatrout Cynoscion nebulosus (Osteichthyes: Sciaenidae) near Charleston, South Carolina. Northeast Gulf Science 12:141-145.

Sprague, M. W., and J. J. Luczkovich. 2001. Do striped cusk eels, Ophidion marginatum (Ophidiidae) produce the 'chatter' sound attributed to weakfish, Cynoscion regalis (Sciaenidae)? Copeia 2001:854-859.

Sprague, M. W., and J. J. Luczkovich. 2004. Measurement of an individual silver perch Bairdiella chrysoura sound pressure level in a field recording. Journal of the Acoustical Society of America 116:3186-3191.

Sprague, M. W., J. J. Luczkovich, R. C. Pullinger, S. E. Johnson, T. Jenkins, and H. J. Daniel, III. 2000. Using spectral analysis to identify drumming sounds of some North Carolina fishes in the family Sciaenidae. Journal of the Elisha Mitchell Society 116:124-145.

Tower, R. W. 1908. The production of sound in the drumfishes, the sea-robin and the toadfish. Annals of the New York Academy of Science 18(part 2):149-180.

Urick, R. J. 1983. Principles of underwater sound. McGrawHill, New York.

Vaughan, D. S., and J. T. Carmichael. 2000. Assessment of Atlantic red drum for 1999: northern and southern regions. NOAA Technical Memorandum NMFS-SEFSC447.

Vaughan, D. S., and J. T. Carmichael. 2002. Estimating improvement in spawning potential ratios for south Atlantic red drum through bag and size limit regulations. North American Journal of Fisheries Management 22:895-906.

Vaughan, D. S., R. J. Seagraves, and K. West. 1991. An assessment of the status of the Atlantic weakfish stock, 1982-1988. Special Report Number 21, Atlantic States Marine Fisheries Commission, Washington, D.C. 